\title{
announcements/call for papers
}

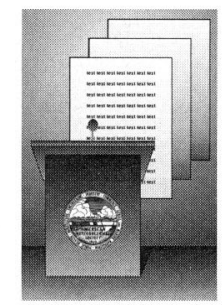

1999 EUMETSAT Meteorological Satellite Data Users' Conference, 6-10 September 1999, Copenhagen, Denmark

The 1999 EUMETSAT Meteorological Satellite Data Users' Conference, organized in cooperation with the DMI, will be held 6-10 September 1999 in Copenhagen, Denmark. The American Meteorological Society is a cooperating organization.

With a new generation of meteorological satellites to be launched early in the next century, the 1999 conference will provide a timely review of the major advances likely to result from new instrumentation. It will also inform users about recent developments. Presentations will address a wide range of meteorological satellite data applications including operational meteorology, climate monitoring, oceanography, sea ice and pollution monitoring, and land surface analysis. Special focus will be placed this year on data applications that will benefit from new satellite instrumentation and processing methods.

The deadline for abstracts has passed. For information contact: Madeleine Pooley, EUMETSAT Info Services, Am Kavalleriesand 31, D-64295 Darmstadt (tel: 496151807 606; fax: 496151807 612; e-mail: pooley@ eumetsat.de; Web: http://www.eumetsat.de). (1/99; r3/99)

International Symposium on Global Change and Protected Areas, 8-16 September 1999, L'Aquila, Italy

An International Symposium on Global Change and Protected Areas will be held at the Auditorium of the National Gran Sasso Laboratories from 8-16 September 1999 in L'Aquila, Italy. The American Meteorological Society is a cooperating organization.

Global change has made it urgent to find early signs of the effect on our environment. Since plants, animals, and the territories they inhabit may be sensitive harbingers of these changes, the biosphere, especially in protected areas such as natural parks, should be monitored. The Abruzzo Region in Central Italy, which has devoted one third of its territory to natural reserves, is organizing this symposium to assess the present status of research in this field.

The meeting will deal with climatic and environmental changes and their impact on the biosphere and hydrology. A section will be devoted to the socioeconomic implication specifically for the protected areas, a case study will be proposed for the Abruzzi Natural Parks. The sym- posium will be organized in sessions opened by invited speakers and followed by short contributions. A special session will be held during the weekend at the Abruzzo National Park.

The deadline for abstracts has passed. For further information visit Web site http://www.aquila.infn.it/gblch. $(4 / 99 ; \mathrm{r} 5 / 99)$

\section{AMS Short Course on Tropical-Extratropical Interaction and Prediction, 12 September 1999, Denver, Colorado}

An AMS Short Course on Tropical-Extratropical Interaction and Prediction, sponsored by the American Meteorological Society, will be held Sunday, 12 September 1999, preceding the 17th Conference on Weather Analysis and Forecasting, the 13th Conference on Numerical Weather Prediction, and the Eight Conference on Climate Variations, in Denver, Colorado. The preliminary program for this short course was published in the July issue of the Bulletin.

This one-day short course will emphasize the potential improvements in predictability to be gained by utilizing knowledge of tropical-extratropical interaction over a broad range of timescales. Topics include 1) Observational evidence of tropical-extratropical interaction at interannual time scales, with an emphasis on the El Niño-Southern Oscillation phenomenon; 2) Observations of the tropical influence on extratropical weather at intraseasonal timescales, with a focus on the Madden-Julian Oscillation and other, higher frequency phenomena; 3) Theoretical basis for the dynamics of tropical-extratropical interaction; and 4) Statistical aspects of tropical-extratropical interaction, emphasizing predictability.

For further information, contact George Kiladis, Aeronomy Laboratory, NOAA/ERL, R/E/AL3, 325 Broadway, Boulder, CO 80303 (tel: 303-497-3892; fax: 303-497-5373; e-mail: gkiladis@al.noaa.gov).

For registration, hotel and general information visit the AMS Web site at http://www.ametsoc.org/AMS, e-mail (amsmtgs@ametsoc.org), or call the AMS Meetings Office (tel: 617-227-2426, ext. 227 or 305). (1/99; r7/99)

\section{7th Conference on Weather Analysis and Forecasting, 13-17 September 1999, Denver, Colorado}

The 17th Conference on Weather Analysis and Forecasting, sponsored by the American Meteorological Soci- 
ety and organized by the AMS Committee on Weather Analysis and Forecasting, will be held 13-17 September 1999 at the Marriott Denver Tech Center in Denver, Colorado. The conference will be held concurrently with the 13th Conference on Numerical Weather Prediction and the Eighth Conference on Climate Variations. The preliminary program for this conference was published in the July issue of the Bulletin.

The focus of the conference will be the analysis and prediction (at 72-hour range and longer) of atmospheric phenomena and processes that are synoptic scale or larger.

The deadline for abstracts has passed. For information, contact Stephen J. Colucci, Dept. of Soil, Crop and Atmospheric Sciences, Bradfield Hall, Cornell University, Ithaca, NY 14853 (tel: 607-255-1752; fax: 607-255-2106; e-mail: colucci@metvax.cit.cornell.edu) or Mary Jo Parker NWS, 1901 S. State Rte. 134, Wilmington, OH 45177 (tel: 937-383-0428; fax: 937-383-0033; e-mail: mary.parker@ noaa.gov). Participants with additional suggestions for the program are encouraged to contact the program chairperson.

For registration, hotel and general information visit the AMS Web site http://www.ametsoc.org/AMS, e-mail: (amsmtgs@ametsoc.org), or call the AMS Meetings Office (tel: 617-227-2426, ext. 305). (9/98; r5/99; r7/99; r9/99)

\section{3th Conference on Numerical Weather Prediction, 13-17 September 1999, Denver, Colorado}

The 13th Conference on Numerical Weather Prediction, sponsored by the American Meteorological Society and organized by the AMS Committee on Weather Analysis and Forecasting, will be held 13-17 September 1999 at the Marriott Denver Tech Center in Denver, Colorado. The conference will be held concurrently with the 17th Conference on Weather Analysis and Forecasting and the Eighth Conference on Climate Variations. The preliminary program for this conference was published in the July issue of the Bulletin.

The deadline for abstracts has passed. The focus of the conference will be the analysis and prediction (at 72-hour range and longer) of atmospheric phenomena and processes that are synoptic scale or larger. Registrants will receive the preprint volume at the conference.

For further information contact, William Burnett, Commander Naval Meteorology and Oceanography Command, CNMOC, 1020 Balch Blvd., Stennis Space Center, MS 39529 (tel: 228-688-4766; fax: 228-688-5791; e-mail: burnett@cnmoc.navy.mil) or Steve Mullen, Department of Atmospheric Sciences, University of Arizona, Tucson, AZ 85721 (e-mail: mullen@air.atmo.arizona.edu). Participants with additional suggestions for the program are encouraged to contact the program chairperson.

\section{Short Course on Tropical-Extratropical Interaction and Prediction 12 September 1999, Denver, Colorado}

GOAL: To examine recent improvements in seasonal global climate prediction and potential improvements in extratropical prediction at the synoptic to seasonal timescales based on the knowledge of tropical influences. To describe the current use of such information in model and statistically based forecast methodologies at the operational level.

FACULTY: Anthony G. Barnston, George N. Kiladis, Chester F. Ropelewski, Joseph Tribbia.

AUDIENCE: Operational meteorologists, researchers, students, consultants.

SYLLABUS - Observational evidence of tropical-extratropical interaction at interannual

INCLUDES: timescales, with an emphasis on the El Niño-Southern Oscillation phenomenon.

- Observations of the tropical influence on extratropical weather at intraseasonal timescales, with a focus on the Madden-Julian Oscillation and other, higher frequency phenomena.

- Theoretical basis for the dynamics of tropical-extratropical interaction.

- Statistical aspects of tropical-extratropical interaction, emphasizing prediction.

ALSO
PROVIDED:

For more information or to register, visit the AMS Web site at http://www.ametsoc.org/AMS and click on "Conferences, Meetings, and Symposia" or contact the AMS Meetings Department at e-mail: amsmtgs@ametsoc.org or call $617-227-2426 \times 227$. 
For registration, hotel and general information visit the AMS Web site at http://www.ametsoc.org/AMS, e-mail (amsmtgs@ametsoc.org), or call the AMS Meetings Office (tel: 617-227-2426, ext. 305). (9/98; r5/99; r7/99)

\section{Eighth Conference on Climate Variations, 13-} 17 September 1999, Denver, Colorado

The Eighth Conference on Climate Variations, sponsored by the American Meteorological Society and organized by the AMS Committee on Climate Variations, will be held 13-17 September 1999 in Denver, Colorado. The preliminary program for this conference was published in the July issue of the Bulletin.

This conference will be held concurrently with the 17th Conference on Weather Analysis and Forecasting and the 13th Conference on Numerical Weather Prediction.

The deadline for abstracts has passed. Posters and papers were solicited on a broad range of climate topics including: 1) Coupled Ocean-Atmosphere Models-Seasonal to Interannual Variability; 2) Coupled Ocean-Atmosphere Models-Decadal Variability; 3) Land Surface Processes in the Climate System; 4) Seasonal Climate PredictionWhere Do We Stand?; and 5) Modulation of Weather by Climate. Joint sessions with the 17 th Conference on Weather Analysis and Forecasting and the 13th Conference on Numerical Weather Prediction have been planned

Registrants will receive the preprint at the conference. For further program information, contact C. F. Ropelewski, IRI for Climate Prediction, 61 Route 9W, RM 207 Oceanography, Palisades, NY 10964-8000 (e-mail: chet@ iri.ldeo.columbia.edu). Participants with additional suggestions for the program are encouraged to contact the program chairperson.

For regitration, hotel and general information visit the at AMS Web site http://www.ametsoc.org/AMS, e-mail (amsmtgs@ametsoc.org), or call the AMS Meetings Office (tel: 617-227-2426, ext. 227). (9/98 r7/99)

Fourth International Conference on Modelling of Global Climate Change and Variability, 1317 September 1999, Hamburg, Germany

The Fourth International Conference on Modelling of Global Climate Change and Variability will be held at the Max-Planck-Institut for Meteorology in Hamburg, Germany, the week of 13-17 September 1999. The American Meteorological Society is a cooperating organization.

The conference will provide an opportunity to present new research results in this field and to discuss recent developments and plans for the future.

The deadline for abstracts has passed. For information contact: Lydia Dümenil, Conference Coordinator, MaxPlanck-Institut for Meteorologie, Bundesstrasse 55, D-20146 Hamburg, Germany (tel: +49 4041173 310; fax: +49 40 41173 366; e-mail: mpi-conference@dkrz.de). (12/98; r3/99)
ANS Seventh Topical Meeting on Emergency Preparedness and Response, 14-17 September 1999, Santa Fe, New Mexico

The American Nuclear Society (ANS) Seventh Topical Meeting on Emergency Preparedness and Response is being held from 14-17 September 1999 in Santa Fe, New Mexico at the La Fonda Hotel. The American Meteorological Society is a cooperating organization.

This meeting is an international forum for the exchange of recent and innovative advances in the preparedness for, mitigation of, and response to nuclear and chemical emergencies. In a format similar to previous topicals on this subject, we are planning a half-day plenary session followed by three parallel tracks, grouping information of similar nature and interest into sessions with individual themes (depending on the spectrum of papers submitted). We have also made arrangements to accommodate an outdoor display of response equipment as well.

Meeting correspondence may be e-mailed to anser99@lanl.gov or faxed to 505-665-4477. For further information visit Web site at http://drambuie.lanl.gov/ ans-er99/. (3/99; r5/99; r6/99)

\section{First Northeast Regional Operational Workshop,} 21-23 September 1999, Albany, New York

The First Northeast Regional Operational Workshop will be held 21-23 September 1999, at the Center for Environmental Science and Technology Management (CESTM) in Albany, New York. The American Meteorological Society is a cooperating organization.

Conference sessios will focus on coastal storms, terrain effects, heavy precipitation forecasting, hydrology, northeast severe storms, lake effect, using high-resolution model data, mesoscale modeling, and integrating new technology into operations.

The deadline for abstracts has passed. Registrants will receive a pre- and postprint of the conference. For more information contact: Jann Joyce, NWS, Suite B300, CESTM, 251 Fuller Rd., Albany, NY 12203 (tel: 518-435-9571; fax 518-435-9587; e-mail: jann.joyce@ noaa.gov).

For conference information, registration forms, hotel and general information refer to Internet address http:// nwsfo.nws.cestm.albany.edu. $(5 / 99 ; 8 / 99)$

\section{Chapman Conference on Water Vapor in the Climate System, 12-15 October 1999, Potomac, Maryland}

The Chapman Conference on Water Vapor in the Climate System, sponsored by AGU, will be held, 12-15 October 1999 in Potomac, Maryland. The American Meteorological Society is a cooperating organization.

Topics to be discussed at this conference include radiative role of water vapor and associated feedback mechanisms; stratosphere-troposphere exchange of water vapor, the hydrological cycle and its potential intensification, the 
role of water vapor in stratospheric chemistry, water vapor in climate models and comparisons with observations, water vapor as a tracer of stratospheric flow, water vapor-cloud interactions, climatology and trends of water vapor and its fluxes in the troposphere and stratosphere, water vapor observations applicable to climate studies. For conference information visit Web site http://www.agu.org/meetings/ cc99bcall.html. To be placed on a mailing list, contact: Kristen Hansen, AGU, Meetings Department, 2000 Florida Ave. NW, Washington, DC 20009 (tel: 1-800-966-2481 in North America or 202-462-6910, ext. 382, outside North America; fax: 202-328-0566; e-mail: khansen@agu.org). $(6 / 99)$

\section{Third International SRNWP: Workshop on Nonhy- drostatic Modelling, 25-27 October 1999, Offenbach, Germany}

The Third International SRNWP: Workshop on Nonhydrostatic Modelling, organized by Deutscher Wetterdienst (DWD), will be held 25-27 October 1999, in Offenbach, Germany. The American Meteorological Society is a cooperating organization. The aim of this workshop is to be a forum for the exchange of information on finescale numerical modelling.

The special topic of the workshop is Data Assimilation for Fine-Scale Models. The deadline for abstracts has passed. For information contact, J. Steppeler, Deutscher Wetterdienst, Frankfurter Str. 135, 63067 Offenbach, Germany (fax: 4969823614 93; e-mail: jsteppeler@ dwd.d400.de). (10/98; 7/99)

\section{4th Annual Climate Diagnostics and Prediction Workshop, 1-5 November 1999, Tucson, Arizona}

The 24th Climate Diagnostics and Prediction Workshop will be held 1-5 November 1999 at the University of Arizona. The workshop is cosponsored by the Climate Prediction Center of the National Centers for Environmental Prediction (NCEP)/NOAA, Washington, D.C., and the University of Arizona's Institute for the Study of the Planet Earth and Institute for Atmospheric Physics, Tucson, Arizona. The American Meteorological Society is a cooperating organization.

The workshop will provide an opportunity for participants to exchange information, ideas, and opinions on a variety of topics, including: review of the 1998-99 climate and an assessment of 1998-99 climate predictions; climate variability and human health; understanding the links between extreme events and climate variability; prediction and diagnosis of monthly and seasonal-to-interdecadal/decadal phenomena (e.g., ENSO, NAO, North Pacific oscillation, Arctic Oscillation, trends, etc.); weather/climate/hydrology issues of particular relevance to the western United States; and climate monitoring capabilities and strategies.

Note that this workshop will include a special session on the relationship between climate variability and human health. This session is intended to develop a robust connection among the climate and health research communities. It will be comprised of both submitted and invited papers, solicited from scientists working on relevant climate variability and health issues that can be either global in nature, or more specifically focused on the western United States.

The deadline for abstracts has passed. Visit the Workshop Web site at http://geo.ispe.arizona.edu/conferences/ climworkshop. (2/99; r4/99; r7/99; r8/99)

\section{Third Conference on Coastal Atmospheric and Oceanic Prediction and Processes, 3-5 November 1999, New Orleans, Louisiana}

The Third Conference on Coastal Atmospheric and Oceanic Prediction and Processes, sponsored by the American Meteorological Society and organized by the AMS Committee on Meteorology and Oceanography of the Coastal Zone, will be held 3-5 November 1999 at the Doubletree Hotel in New Orleans, Louisiana. The preliminary program for this conference is published in this issue of the Bulletin.

The purpose of this conference is to strengthen the scientific and technical communications between meteorologists and physical oceanographers involved in this topic area, from research and operational perspectives, at a time when both NOAA (NWS, NOS, and OAR) and the navy (ONR and CNMOC), and their European and Asian counterparts, continue their pioneering $R \& D$ and operational steps toward coastal atmospheric and oceanic prediction. Thus, as the third conference on this topic, the hope is that it will further strengthen the community of involved and interacting scientists and stimulate further progress.

The conference will address research, development, and operational issues and activities bearing on the prediction of coastal atmospheric weather and oceanic transient flows and air-sea transfers. Here, "coastal" pertains to the domain within approximately $300 \mathrm{~km}$ from the coastline, and "prediction" encompasses simulation as well as hindcasting, nowcasting, and forecasting. Process studies as well as observing, modeling, and data assimilation systems will be addressed. In particular the following are of interest: 1) the utilization of satellite, coastal radar, and other remote sensing systems; 2) the exploration of coastal atmosphere-ocean coupling processes; and 3) the design and performance of prototype coastal prediction systems.

The conference will meet jointly with the Conference on Estuarine and Coastal Modeling (ECM), which attracts leading authorities from the international modeling and ocean engineering communities. Joint sessions between the two conferences are planned and participants from either conference are encouraged and welcomed to attend.

The deadline for abstracts has passed. Registrants will receive the preprint volume at the conference.

For additional information contact either one of the program cochairpersons: Marshall D. Earle, Neptune Sciences, Inc., 12310 Pinecrest Rd, Suite 203, Reston, VA 
20191 (tel: 703-620-5858; fax: 703-620-3900; e-mail: mearle@neptunesci.com) or Nicholas A. Bond, NOAA/ PMEL, 7600 Sand Point Way NE, Seattle, WA 98115 (tel: 206-526-6459; fax: 206-526-6485; e-mail: bond@ pmel.noaa.gov). Participants with additional suggestions for the program are encouraged to contact the program chairperson. For registration, hotel and general information visit the AMS Web site http://www.ametsoc.org/ AMS, e-mail (amsmtgs@ ametsoc.org), or call the AMS Meetings Office (tel: 617-227-2426, ext. 226). (8/98; r9/98; r3/99; r6/99; r9/99)

\section{Sixth International Conference on Estuarine and Coastal Modeling (ECM6), 3-5 November 1999, New Orleans, Lovisiana}

The Sixth International Conference on Estuarine and Coastal Modeling (ECM6) will be held 3-5 November 1999 at the Doubletree Hotel in New Orleans, Louisiana. The American Meteorological Society is a cooperating organization.

The conference is meeting jointly with the AMS Third Conference on Coastal Atmospheric and Oceanic Prediction and Processes. Joint sessions between are planned and participants from either conference are encouraged and welcomed to attend these sessions.

The focus of the conference is on the development and application of estuarine and coastal circulation and pollutant transport and fate models to solve engineering and environmental assessment problems. Topics of interest include circulation modeling, pollutant transport and water quality prediction, modeling techniques and sensitivity studies, model-data comparison methods, specific estuarine and coastal system models, water level and current forecasting, visualization in model/data analysis, sediment transport modeling, modeling of chemicals and floatables, hazardous waste fate prediction, inverse methods and facility siting and CSO studies.

Several sessions of the ECM6 conference will be held jointly with the AMS Third Conference on Coastal Atmospheric and Oceanic Prediction and Processes, also to be held 3-5 November 1999, in New Orleans, Louisiana. Sponsored by the American Meteorological Society and organized by the AMS Committee on Meteorology and Oceanography of the Coastal Zone, this conference aims to strengthen the scientific and technical communications between meteorologists and physical oceanographers involved in this topic area, from research and operational perspectives. The deadline for abstracts has passed. For further information visit the conference Web site at http:// www.oce.uri.edu/emc6. (4/99; r6/99; r9/99)

\section{ICB-ICUC'99 Conference, 8-12 November 1999, Sydney, Australia}

The ICB-ICUC' 99 Conference (15th International Conference of Biometeorology and International Conference on
Urban Climatology), sponsored by Macquarie University, World Meteorological Organization and the International Society of Biometeorology, will be held 8-12 November 1999 in Sydney, Australia. The American Meteorological Society is a cooperating organization.

The focus of this conference is "Biometeorology and Urban Climatology at the Turn of the Millennium." For information please contact: Tour Hosts Pty Ltd, ICBICUC'99 Secretariat, GPO Box 12, Sydney NSW 2001, Australia (tel: 612 9262 3135; fax: 6129262 2277; e-mail: ICBICUC@tourhosts.com.au) or refer to Web site http:// www.es.mq.edu.au/ICB-99/. (5/98; r6/98; r8/98)

\section{International Conference on Air Quality Manage- ment, 15-17 November 1999, Darussalam, Brunei}

An International Conference on Air Quality Management, sponsored by the University of Brunei, will be held 15-17 November 1999 in the University of Brunei. Professor M. P. Singh is the convener.The American Meteorological Society is a cooperating organization. A two-day workshop on Air Quality Modeling will follow the conference. There will be a mini symposium on haze as part of the conference.

Sessions on Air Quality problems related to Southeast Asia, Air Quality Modeling and Air Quality Management

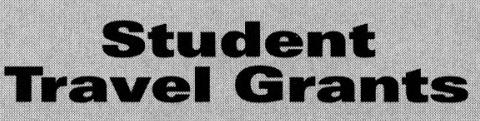

Student Travel Grants are available for senior undergraduate and graduate students to attend AMS meetings held in the United States and Canada. The travel grants are available only to members, including student members, of the AMS.

AMS recognizes the considerable benefit that students can gain from attending conferences even if they are not presenting a paper there, and AMS wants to encourage interactions between students and other conference attendees. To this end, travel grants will be awarded to a student who is not presenting a paper at the conference.

Students who are presenting papers and potentially in need of travel support should inquire of the program chair whether any funds will be available for this purpose.

For more information and to complete an application form, please visit the AMS Web site at www.ametsoc.org/AMS. 
are planned. Papers on El Niño and La Niña and their influence on air quality problems such as forest fires and haze are also invited.

For further information contact, Lim Chui Hua, Assistant Registrar, Faculty of Science, Universiti Brunei Darussalam, Jalan Tugku Link, Gadong BE 1410 Brunie Darussalam (e-mail: haz@ubd.edu.bn; fax 673-2-249502). (2/99; r6/99; r7/99; r9/99)

\section{Sixth Workshop on Operational Meteorology, 29 November-3 December 1999, Halifax, Nova Scotia, Canada}

The Sixth Workshop on Operational Meteorology, sponsored by Environment Canada will be held 29 November-3 December 1999 in Halifax, Nova Scotia, Canada. The American Meteorological Societ is a cooperating organization.

The deadline for abstract has passed. Proceedings will be published and distributed subsequent to the workshop, with papers due at the time of the workshop in November 1999.

For further information please contact Jim Abraham, Program Chair, Environment Canada, 45 Alderney Drive, Dartmouth, NS B2Y 2N6, Canada (tel: 902-426-9134; fax: 902-426-9158; e-mail: jim.abrham@ec.gc.ca). (11/98; r2/99; r5/99; r6/99)

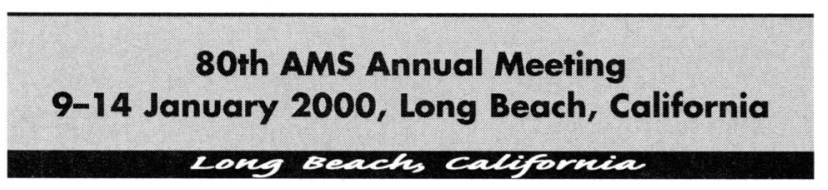

\section{0th AMS Annual Meeting Conferences and Symposia}

The 80th Annual Meeting of the American Meteorological Society will be held 9-14 January 2000 at the Long Beach Convention Center in Long Beach, California.

The following conferences and short courses have been scheduled for the 80th AMS Annual Meeting: Short Course on Becoming a Weather Entrepreneur; Short Course on Introduction to Data Mining Knowledge Discovery from Databases; Short Course on Land Surface-Climate Interaction; Short Course on Mesoscale Atmospheric Modeling by Original Model Developers; Short Course on National Weather Service (NWS) Data Sources, Formats, \& Use; Second Symposium on Environmental Applications; 16th International Conference on Interactive Information and Processing Systems (IIPS) for Meteorology, Oceanography, and Hydrology; 15th Conference on Hydrology; 11th Joint Conference on the Applications of Air Pollution Meteorology with the AWMA; 11th Symposium on Global Change Studies; 11th Conference on the Middle Atmosphere; 10th Conference on Satellite Meteorology and Oceanography; Ninth Symposium on Education; Fourth Symposium on Integrated Observing Systems; Third Symposium on Fire and Forest Meteorology; Second Conference on Artificial
Intelligence; Symposium on Atmospheric Chemistry Issues in the 21st Century Symposium on Lidar Atmospheric Monitoring; Symposium on the Mystery of Severe Storms: A Tribute to the Work of T. Theodore Fujita; and Symposium on Project VORTEX: What We Have Learned-Where We Must Go. (12/98; r3/99; r7/99)

\section{0th AMS Annual Meeting Theme}

This year's theme is "Applying Environmental Science to Societal Needs in the New Millennium." Issues related to this theme will be covered in several of the conferences making up the Annual Meeting and will be highlighted in the Second Symposium on Environmental Applications. In addition, several conferences and symposia will also address issues related to the international assessment underway in the IPCC, to stratospheric and tropospheric ozone, and to the national assessment which is scheduled to be completed by the time of the meeting.

\section{AMS Short Course on Becoming a Weather Entrepreneur, 9 January 2000, Long Beach, California}

An AMS Short Course on Becoming a Weather Entrepreneur, sponsored by the AMS and organized by the AMS Board on Private Sector Meteorology, and cosponsored by the National Council of Industrial Meteorologists, will be held on Sunday, 9 January 2000, preceding the 80th AMS Annual Meeting in Long Beach, California.

In today's business world, a major shift to out-sourcing for technical services has occurred in lieu of budget cuts, downsizing, and layoffs. Are you considering broadening your options by starting a weather consulting business as you prepare for the your long-term career path? Or, are you hampered by limited opportunities in your present position? In fact, there are many valid reasons why an individual may want to pursue consulting as a part or even full-time practice. Multitudes of information sources are available for starting a small business, however, the information on starting your own weather business venture is greatly limited.

In this short course, you will learn about ins and outs of starting your own weather consulting business, from the successful voice of experience - those who have created a profitable weather consulting business. Learn about the components of a successful weather entrepreneur, business plans, and related business necessities such as marketing, proposal writing, customer relationships, and government assistance plans. The ultimate decision to start one's own business is a difficult one, and depends on personal finances and lifestyle preferences, as well as technical skills, capabilities, and individual creativity and desire. The goal of this course is provide real information on the private weather consulting business to help you make the decision whether to venture into this potentially profitable and self-satisfying career path. 
For further information contact: Matthew J. Parker, Organizing Committee Chairman, Senior Meteorologist, Savannah River Technology Center, Bldg. 735-7A, Aiken, SC 29808 (tel work: 803-725-2805; tel home: 706-8556397; fax: 706-869-1841; e-mail: parker@groupz.net) or Phillip Falconer, Falconer Weather Information Services, 7 Via Maria Drive, Scotia, NY 12302-5717

For registration, hotel and general information visit the AMS Web site at http://www.ametsoc.org/AMS, e-mail (amsmtgs@ametsoc.org), or call the AMS Meetings Office (tel: 617-227-2426, ext. 226, 227, or 305). (tel: 518-3995388; fax: 518-399-5320). (4/99)

\section{AMS Short Course on Introduction to Data Mining and Knowledge Discovery from Databases, 9 January 2000, Long Beach, California}

An AMS Short Course on Introduction to Data Mining and Knowledge Discovery from Databases, sponsored by the American Meteorological Society, will be held as part of the 80th AMS Annual Meeting, 9 January 2000.

This course is being presented to provide an overview and introduce the principles of data mining. Data mining refers to the specific algorithms applied to datain order to extract patterns. Recent advances in data collection and computing power have created a need for a greater variety and more sophisticated methods of data reduction and analysis. These methods are collectively grouped in the field of knowledge discovery from databases (KDD), which refers to the overall process of discovering useful information from data. The application of data mining, especially in terms of meteorological problems, will be discussed and the available tools will be reviewed. Topics may include 1) what is data mining and when to use it, 2) goals of data mining, 3) knowledge discovery from databases, 4) data warehousing, 5) available mining tools, 6) determining the appropriate tool/methodology, and 7) current application examples.

For further information, contact Richard L. Bankert, Naval Research Laboratory, 7 Grace Hopper Ave., Monterey, CA 93943-5502 (tel: 831-656-4880; fax: 83156-4769; e-mail: bankert@nrlmry.navy.mil).

For registration, hotel and general information visit the AMS Web site at http://www.ametsoc.org/AMS, e-mail (amsmtgs@ametsoc.org), or call the AMS Meetings Office (tel: 617-227-2426, ext. 226, 227, or 305). (5/99)

\section{Announcement}

\section{AMS Short Course on Land Surface-Climate Inter- action, 9 January 2000, Long Beach, California}

An AMS Short Course on Land Surface-Climate Interaction, sponsored by the American Meteorological Society and organized by the AMS Committee Hydrology, will be held Sunday, 9 January 2000 preceding the 80th AMS Annual Meeting in Long Beach, California.
Land surface-climate interaction is a new scientific field, and the results in this field have significant scientific implications. This course is suitable for students and scientists who desire an introduction to the basic concepts and areas of studies in this field. The lectures include Introduction (the development of land surface-climate interaction studies during the past two decades); Atmospheric modeling (basic structures of general circulation models (GCMs) will be presented, including an example using a GCM); Land surface Modeling (main components in a land surface model); Land model comparisons (the results from the Projects for Intercomparison of Land Parameterization Schemes will be introduced); Land-atmosphere coupling (the methodologies and principles for land-atmosphere coupling); Climate studies using coupled models (the application and uncertainty) and a tutorial class with PCs for students to practice using a land surface model.

The course includes a luncheon and will be taught by Yongkang Xue (Univeristyof Maryland) and Andrea Halmann (University of Arizona), as well as other faculty drawn from the joint session on this subject to be held at the Annual Meeting. For further information, please contact: Yongkang Xue, Department of Geography, University of Maryland, College Park, MD 20742 (tel: 301-405-5880; fax: 301-314-9299; e-mail: yxue@ geog.umd.edu).

\section{AMS Short Course on Mesoscale Atmospheric Modeling by Original Model Developers, 9 January 2000, Long Beach, California}

An AMS Short Course on Mesoscale Atmospheric Modeling by Original Model Developers, sponsored by the American Meteorological Society and organized by the AMS Committee on Weather Analysis and Forecasting Committee, will be held Sunday, 9 January 2000 preceding the 80th AMS Annual Meeting in Long Beach, California.

This one-day short course is designed to assist students interested in learning about atmospheric modeling, professors teaching atmospheric modeling, researchers involved in modeling or wanting to know the differences between various models, and managers needing to decide on which models to use for their projects.

Models are sometimes misrepresented and misused. The course will provide a unique opportunity in learning directly from the original model developers on their models and the differences between the models. The course will begin with presentations on the technical and scientific design considerations. Following these presentations, the speakers will participate in a panel discussion, which will focus on the challenges that modelers encounter and limitations of mesoscale modeling.

This course will be taught by one of the original developers of each of the following models: RAMS, MM5 COAMPS, HOTMAC, FINTAH, and ARPS. For further information please contact: Sayuri Yamada, Yamada Science \& Art Corporation (YSA), Route 4 Box 81-A, Santa 
Fe, NM 87501 (tel: 505-989-7351; fax: 505-989-7965; e-mail: ysa@ysasoft.com).

For registration, hotel and general information visit the AMS Web site at http://www.ametsoc.org/AMS, e-mail (amsmtgs@ametsoc.org), or call the AMS Meetings Office (tel: 617-227-2426, ext. 226, 227, or 305). (6/99)

\section{AMS Short Course on National Weather Service (NWS) Data Sources, Formats, \& Use, 9 January 2000, Long Beach, California}

An updated edition of this popular AMS Short Course on NWS Data Sources, Formats, \& Use, sponsored by the American Meteorological Society and organized by the National Weather Service, will be held Sunday, 9 January 2000, in Long Beach, California, preceding the 80th AMS Annual Meeting.

The goal of this one-day short course is to provide an in-depth discussion of the many sources of meteorological data from sources operated in the NWS, along with a description of the data format. Technical experts from the NWS and/or its contractors in the areas of telecommunications, data format, and model output parameters will be conducting this short course. Anyone interested in using any of the NWS sources of data, including operational meteorologists, exhibitors, students, attendees from educational institutions, or foreign attendees are welcome.

The syllabus will include the following: 1) technical descriptions of the NWS Family of Services and NWS Internet file server, AWIPS/NOAAPORT, and the World Area Forecast System (WAFS), and EMWIN; 2) technical descriptions of the data streams found on the different NWS services; 3 ) technical descriptions of the data format, such as BUFR, GRIB, NOAAPORT satellite, found on NWS services and the WMO message heading addressing scheme; 4) a description of the process used by NWS to manage the data found on these services; and 5) a description of the NCEP model output parameters and a short discussion of NCEP's future model and product development. A luncheon will be included in this day of events.

Also provided will be reference material which the student can consult in the future, software demonstrations, lists of contact points and addresses. For further information contact: Richard Thigpen, NWSW/APO3, 1325 East-West Highway, Silver Spring, MD 20910 (tel: 301713-0920; fax: 301-713-0173; e-mail: richard.thigpen@ noaa.gov).

For registration and hotel \& general information, please contact the AMS Meetings Dept. (tel: 617-227-2426, x226, 227, 228, or 305; fax:617-742-8718; e-mail:amsmtgs@ ametsoc.org). (7/99)

\section{Second Symposium on Environmental Applications, 9-14 January 2000, Long Beach, California}

The Second Symposium on Environmental Applications, sponsored by the American Meteorological Society, will be held as part of the 80th AMS Annual Meeting, 914 January 2000 in Long Beach, California.

The central theme of the 80th Annual Meeting is "Applying Environmental Science to Societal Needs in the New Millennium." This symposium, together with concurrent conferences and symposia such as air pollution meteorology, satellite meteorology and oceanography, severe local storms, hydrology, and global change, will provide an overall picture of the applications of meteorology today.

A special session on environmental extremes and their impact on society is being developed under the eadership of President-elect George L. Frederick Jr. in collaboration with the AMS Board of Private Sector Meteorology, the AMS Committee on Societal Impacts, and the chairs of the Symposia on Severe Local Storms and Global Change. Each session will begin with an invited keynote overview paper. Papers were solicited on applied meteorology topics relating to areas such as alternate energy systems (including wind and nuclear), energy use and design, architecture and construction, biometeorology and aerobiology, fire/forest meteorology, planned and inadvertent weather modification, coastal oceanic and atmospheric prediction, forensics, human health, water resources (quality and quantity), space weather, agriculture, insurance, transportation [including meteorological aspects of the Intelligent Transportation System (ITS)], ecosystem and natural resource management, natural hazard mitigation strategies, and decision making under a sustainable development framework. Participants with additional suggestions for the program are encouraged to contact the program chairperson.

The deadline for abstracts is has passed. A preprint volume is planned and authors of accepted abstracts are encouraged to contribute to this volume. Instructions for formatting extended manuscripts for the preprint volume will be posted on the AMS Web site. Camera-ready manuscripts (page length to be determined), including photos and diagrams, must be submitted by 1 October 1999 to AMS Headquarters. Page charges will be assessed to defray printing costs. Registrants will receive the preprint volume at the conference.

For further information contact: George L. Frederick, Jr., Radian Electronic Systems, 15705 Long Vista Drive, Austin, TX 78728 (tel: 512-989-4308; fax: 512-251-4804; e-mail: George_Frederick@ radian.com).

For registration, hotel and general information visit the AMS Web site at http://www.ametsoc.org/AMS, e-mail (amsmtgs@ametsoc.org), or call the AMS Meetings Office (tel: 617-227-2426, ext. 226, 227, or 305). (12/98; r7/99)

\section{6th International Conference on Interactive Information and Processing Systems (IIPS) for Meteorology, Oceanography, and Hydrology, 9- 14 January 2000, Long Beach, California}

The 16th International Conference on IIPS for Meteorology, Oceanography, and Hydrology, sponsored by the 
American Meteorological Society and organized by the AMS Committee on IIPS, will be held as part of the 80th AMS Annual Meeting, 9-14 January 2000 in Long Beach, California.

The central theme of the 80th Annual Meeting is “Applying Environmental Science to Societal Needs in the New Millennium."

This applied interactive technology conference brings together the government and private sectors, both international and national, and those who supply or use data and information systems and technology. Emphasis for this conference will be on the IIPS systems that enable or enhance the capabilities of the weather and climate communities, and contribute to the development or provision of services to the public or private sectors, including observations, diagnostics, research, and applications.

Preliminary IIPS sessions are planned on interdisciplinary applications; status of modernization activities of government and commercial weather services; technology and technique development at laboratories and in industries associated with meteorology, hydrology, and oceanography; and applications of IIPS using radar, satellites, other observation platforms, and their associated data processing systems. Special sessions are also planned on applications of decision support tools in the use and leverage of the Internet; hydrology; metadata; military applications of such systems; the overall economic benefits of weather information; and a wrap on Year 2000 issues and problems. Joint sessions are planned with other conferences and symposia planned for this meeting, including the Second Symposium on Environmental Applications, which will feature a joint session on surface transportation and the environment, following-up on topics introduced at the 1998 and 1999 conferences, including the impacts of the natural environment on road, rail and waterway modes of transportation.

International aspects of IIPS will apply to most of these topic areas, but a special session will feature European applications. Subjects will range from observing systems, communications systems, analysis and forecasting systems, dissemination systems to special services needed to serve the surface transportation industry, including transportation management centers and traffic flow control. Members are encouraged to contact the program chair with questions or suggestions regarding these or additional topics, or other program aspects of this conference participants with additional suggestions for the program are encouraged to contact the program chairperson.

As part of the AMS 2000 IIPS Conference, the Air and Space Natural Environment Modeling and Simulation Executive Agent (ASNE MSEA) is hosting a special half-day session on "Department of Defense (DoD) Environmental Modeling and Simulation (M\&S)." As the air and space environmental subject matter experts for DoD $M \& S$, the ASNE MSEA is building an infrastructure to ensure $M \& S$ customers can obtain consistent environmental representations for their specific needs.

Historically, realistic weather has played little in simulations; it has been either too hard to do or too expensive. However, three large DoD M\&S programs Joint Simulation System (JSIMS), Joint Warfare System (JWARS), and Joint Modeling and Simulation System (JMASS) currently in development will interact with the air, space, ocean, and terrain domains by accounting for the effects of the environment on simulation objects (aircraft, ships, tanks, weapon systems, personnel, etc.). The ASNE MSEA is sponsoring a number of projects that will ensure natural environment data providers can support these simulation programs.

More information about DoD M\&S, and specifically ASNE MSEA-supported projects, may be obtained through the ASNE MSEA Web Site at http://msea.afccc.af.mil/.

The deadline for abstracts has passed. A preprint volume is planned and authors of accepted abstracts are encouraged to contribute to this volume. Instructions for formatting extended manuscripts for the preprint volume will be posted on the AMS Web site.

Camera-ready manuscripts (page length to be determined), including photos and diagrams, must be submitted by 1 October 1999 to AMS Headquarters. Page charges will be assessed to defray printing costs. Registrants will receive the preprint volume at the conference.The conference will include exhibits and demonstrations that continue to be popular and help to illustrate the practicality of using offthe-shelf, demonstrated marketable systems and software tailored to meet the needs of meteorology, oceanography, and hydrology. Potential exhibitors should contact Elizabeth Miller, AMS, 1200 New York Avenue, Suite 410, Washington, DC 20005 (tel: 202-682-9006; e-mail: emiller@dc.ametsoc.org). The IIPS Program Committee encourages authors to use computers and video equipment in support of their oral and poster presentations. Largescreen projection systems for data and video presentations will be available during the conference. There will also be access to a T1 Internet line for support of oral and poster presentations.

For more detailed information and audio/visual aids, available computer equipment, and suggestions for your presentations please consult the AMS Home Page (http:// ametsoc.org/AMS). For further information, contact Conference Chairperson: Floyd F. Hauth, (USAF, retired), 379 Spike Island Road, Osceola Mills, PA 16666 (tel: 814-3397778; fax: 814-339-7773; e-mail: fhauth@ srt.net). For registration, hotel and general information visit the AMS Web site at http://ww.ametsoc.org/AMS, e-mail (amsmtgs@ ametsoc.org), or call the AMS Meetings Office (tel: 617227-2426, ext. 226). (12/98; r3/99; r7/99) 
15th Conference on Hydrology, 9-14 January 2000, Long Beach, California

The 15th Conference on Hydrology, sponsored by the American Meteorological Society and organized by the AMS Committee on Hydrology, will be held as part of the 80th AMS Annual Meeting, 9-14 January 2000 in Long Beach, California. The theme of the annual meeting is "Applying Environmental Science to Societal Needs in he Next Millennium."

Issues related to this theme will be highlighted in this symposium by soliciting submissions that focus on new observations and advances in hydrologic sciences, a greater appreciation of linkages between terrestrial and water systems, demonstration that these advances are beneficial to water resources managers and bring insights to issues related to the international assessment underway in the IPCC.

The deadline for abstracts has passed. Papers were solicited in following areas: 1)Terrestrial Biosphere Feedback to the Atmosphere at the Regional and Global Scales, 2) Heavy Precipitation and Flash Flooding, 3) Hydrological and Hydrometeorological Impacts Due to Climate Change, 4) TRMM Hydrology, and 5) Data, Modeling and Analysis in Hydrometeorology. Sessions may be developed that focus on land-atmospheric coupling, including boundary layer studies; advances in hydrological modeling and land surface data assimilation systems; and diagnostic studies of regional climate systems, including cold season and highlatitude areas.

Participants with suggestions for the program are encouraged to contact the program chairperson.

A preprint volume is planned and authors of accepted abstracts are encouraged to contribute to this volume. Instructions for formatting extended manuscripts for the preprint volume will be posted on the AMS Web site. Camera-ready manuscripts for the conference proceeding volume (page length to be determined) must be submitted by 1 October 1999 to AMS Headquarters. Page charges will be assessed to defray printing costs. Registrants will receive the preprint volume at the conference.

For information, contact either James A. Smith (e-mail: jsmith@radap.princeton.edu) or Eric F. Wood (e-mail: efwood@princeton.edu). For general information visit the AMS Web site at http://www.ametsoc.org/AMS, e-mail (amsmtgs@ametsoc.org), or call the AMS Meetings Office (tel: 617-227-2426, ext. 305). (12/98; r7/99; r8/99)

\section{1 th Joint Conference on the Applications of Air Pollution Meteorology with the Air and Waste Management Association, 9-14 January 2000, Long Beach, California}

The 11th Joint Conference on the Applications of Air Pollution Meteorology with the Air \& Waste Management Association (AWMA), sponsored by the American Meteorological Society and organized by the AMS Committee on the Meteorological Aspects of Air Pollution (CMAAP), will be held 9-14 January 2000 as part of the 80th AMS Annual Meeting in Long Beach, California.

This conference will address atmospheric disperson and air pollution meteorology with a focus on the integration of models, experiments, and observations to improve the realism of air quality models and predictions in the new millennium. The conference will cover fundamental aspects of dispersion (theories, experiments, field observations), dispersion applications, and air pollution meteorology and chemistry. The general topical areas include gaseous and aerosol dispersion, deposition, factors affecting the dispersion environment (turbulence, boundary layer processes, source conditions, etc.), terrain and building influences, chemistry, and instruments and measurement systems.

Both poster and oral presentations were solicited within the general areas of atmospheric dispersion and air pollution meteorology and chemistry. In addition, there will be a few invited speakers, and joint sessions are planned with the Symposium on Atmospheric Chemistry Issues in the 21st Century.

The deadline for abstracts has passed. Specific topical areas sought include 1) dispersion in the stable atmospheric boundary layer, 2) dispersion in the convective and transitional boundary layers, 3 ) dispersion about buildings and obstacles, 4) flow and dispersion in coastal and complex terrain, 5) meso- and regional-scale dispersion, 6) photochemical and other chemistry-oriented air quality models, 7) particulates, aerosols, and related phenomena (e.g., deposition), 8) the urban environment - meteorology, dispersion, and air quality, 9) instantaneous and accidental releases, 10) concentration fluctuations, model uncertainty and evaluation, 11) integrated modeling/measurement systems for emissions and air quality predictions, and 12) advanced modeling techniques for dispersion on all scales.

A preprint volume is planned and authors of accepted abstracts are encouraged to contribute to this volume. Instructions for formatting extended manuscripts for the preprint volume will be posted on the AMS Web site. Camera-ready manuscripts (page length to be determined), including photos and diagrams, must be submitted by 1 October 1999 to AMS Headquarters. Page charges will be assessed to defray printing costs. Registrants will receive the preprint volume at the conference.

For further information contact: Jeffrey C. Weil, CIRES, University of Colorado, CB 216, Boulder, CO 80309 (tel: 303-497-8907; fax: 303-497-8171, e-mail: weil@ncar.ucar.edu). For registration, hotel and general information visit the AMS Web site at http://www. ametsoc.org/AMS, e-mail (amsmtgs@ametsoc.org), or call the AMS Meetings Office (tel: 617-227-2426, ext. 227). (12/98; r3/99; r5/99; r7/99; r8/99)

\section{$11^{\text {th }}$ Symposium on Global Change Studies, 9- 14 January 2000, Long Beach, California}

The 11th Symposium on Global Change Studies, sponsored by the American Meteorological Society, will be held 
as part of the 80th AMS Annual Meeting, 9-14 January 2000 in Long Beach, California.

The meeting will be devoted to a number of themes including 1) U.S. National Climate Assessment; 2) Intergovernmental Panel on Climate Change (IPCC) Third Assessment Report; and 3) advancing our understanding of the interrelationships between decadal-to-centennial and seasonal-to-interannual climate variability and changes. In particular, areas to be addressed include climate modeling and issues related to scale; climate forcing factors such as clouds, water vapor, aerosols, and the carbon cycle; climate change detection and attribution; and paleoclimate studies of the past 1000 years.

Joint sessions are planned with the 10th Conference on Satellite Meteorology and Oceanography on long-term climate studies using satellite data; he Symposium on Lidar Atmospheric Monitoring on using lidar for long-term monitoring related to climate research; the Second Symposium on Environmental Applications with the Committee on Societal Impacts on current and potential impacts of extreme events; and the 15th Conference on Hydrology on biosphere-atmosphere interactions including results from recent GCM and mesoscale land surface experiments that help quantify surface-atmosphere feedbacks and interactions, as well analyses based on either remotely sensed or in-situ observational system, such as FLUXNET.

The deadline for abstracts has passed. Papers were solicited on these themes or any others directly addressing global change. A preprint volume is planned and authors of accepted abstracts are encouraged to contribute to this volume. Instructions for formatting extended manuscripts for the preprint volume will be posted on the AMS Web site. Camera-ready manuscript (page length to be determined at a later date), including photos and diagrams, must be submitted by 1 October 1999 to AMS Headquarters. Page charges will be assessed to defray printing costs. Registrants will receive a preprint volume at the conference.

For further information please contact one of the Cochairpersons: David R. Easterling or Thomas R. Karl, NOAA/NCDC, 151 Patton Avenue, Asheville, NC 28801 (tel: 828-271-4311; fax: 828-271-4328; e-mail: deasterl@ ncdc.noaa.gov or tkarl@ ncdc.noaa.gov).

For registration, hotel and general information visit the AMS Web site at http://www.ametsoc.org/AMS, e-mail (amsmtgs@ametsoc.org), or call the AMS Meetings Office (tel: 617-227-2426, ext. 227). (12/98; r4/99; r5/99; r7/99; r8/99)

\section{$11^{\text {th }}$ Conference on the Middle Atmosphere, 9- 14 January 2000, Long Beach, California}

The 11th Conference on the Middle Atmosphere, sponsored by the American Meteorological Society and organized by the AMS Committee on the Middle Atmosphere, will be held 9-14 January 2000 as part of the 80th AMS Annual Meeting in Long Beach, California.
The theme of the 80th AMS Annual Meeting is “Applying Environmental Science to Societal Needs in the New Millennium."

The deadline for abstracts has passed. Papers were solicited in all areas of middle atmosphere science, including dynamics, trace constituent transport, chemistry, and radiation. We sought a balanced program of observational studies, modeling, and theory. Specific scientific topics to be addressed will include 1) trace constituent transport and mixing, especially in the Tropics and subtropics; 2) dynamical and chemical coupling between the troposphere and middle atmosphere; 3) stratospheric chemistry; 4) aerosols; 5) long-term variability of trace constituents \& dynamics; 6) mesospheric processes; 7) gravity waves; and 8) chemical transport models and data assimilation. Participants with additional suggestions for the program are encouraged to contact the program chairperson.

Papers were also solicited for a joint session with the Conference on Satellite Meteorology and Oceanography on the use of satellite observations in middle atmosphere studies. This session will be part of the Satellite Conference theme of "Retrieval of Atmospheric Profiles and Constituents" and will consist primarily of posters with a small number of invited talks. A special block of time will be set aside for the poster session.

In addition, five awards of $\$ 200$ each will be made for the best student presentations of the conference. Both oral and poster presentations will be considered for awards.

No preprint is planned.

For further information contact: Kenneth P. Bowman Department of Meteorology, Texas A\&M University, College Station, TX 77843-3150 (tel: 409-862-4060; fax: 409862-4466; e-mail: k-bowman@tamu.edu).

For registration, hotel and general information visit the AMS Web site at http://www.ametsoc.org/AMS, e-mail (amsmtgs@ametsoc.org), or call the AMS Meetings Office (tel: 617-227-2426, ext. 305). (12/98; r4/99; r5/99; r7/99)

\section{0th Conference on Satellite Meteorology and Oceanography, 9-14 January 2000, Long Beach, California}

The 10th Conference on Satellite Meteorology and Oceanography, sponsored by the American Meteorological Society and organized by the AMS Committee on Satellite Meteorology and Oceanography, will be held as part of the 80th AMS Annual Meeting, 9-14 January 2000 in Long Beach, California.

The theme of the 80th Annual Meeting is "Applying Environmental Science and Societal Needs in the New Millennium." Appropriately, the 10th Conference on Satellite Meteorology and Oceanography will structure several of its sessions to focus on this topic. The conference will also include joint sessions with the 11th Conference on Middle Atmosphere, the 11th Symposium on Global Change Studies, and the Second Conference on Artificial 
Intelligence. In addition, the conference will cosponsor the GOES/POES evening session with the 16th Conference on Interactive Information and Processing Systems. To celebrate the 40th anniversary of the first TIROS launch (1 April 1960), the conference will feature a variety of invited speakers and displays celebrating this milestone in satellite meteorology!

The conference will be an all poster format with few invited oral overview presentations. Invited plenary presentations and contributed presentations on topical issues of broad interest will be used to set the themes of each day. To provide authors with sufficient time to discuss their research and to foster closer interaction among attendees, all other papers will be posters. Each session or day will be concluded in plenary with an interactive discussion of poster topics and themes. The general themes for each day are listed below.

The deadline for abstracts has passed. Poster papers were solicited to cover any of these five broad areas of interest: 1) Environmental Applications of Land and Oceanic Remote Sensing, 2) Climatology and Long-Term Satellite Data Studies, 3) Operational Applications. Subject areas include real-time applications of POES and GOES measurements and products, satellite data assimilation techniques, forward models, and impact studies, etc., 4) Retrieval of Atmospheric Profiles and Constituents; and 5) New Technology. Includes both new sensors (i.e., NPOESS, AMSU, EOS, etc.) and new processing/retrieval techniques (i.e., neural networks, error analysis, multisensor techniques, etc.). This theme will include a joint session with the Second Conference on Artificial Intelligence. Participants with additional suggestions for the program are encouraged to contact the program chairperson.

The conference program committee especially invites students to be an integral part of the conference. Poster that were identified as student submissions (primary author) on the abstract were automatically entered in a student poster contest, with cash prizes and certificates that will be awarded at the conference. A panel of judges will select winners at the time of the poster viewing.

A preprint volume is planned and authors of invited and accepted poster papers will be required to contribute to this volume. Submittal of a written paper is required to guarantee poster space, which will be limited. This requirement will be strictly enforced. Instructions for formating extended manuscripts for the preprint volume will be posted on the AMS Web site. Camera-ready manuscript (page length to be determined at a later date), including photos and diagrams, must be submitted by 1 October 1999 to AMS Headquarters. Page charges will be assessed to defray printing costs. Registrants will receive a preprint volume at the conference.

For information, contact Ralph Ferraro, Office of Research \& Applications, E/RA2, WWB Room 601, NOAA/ NESDIS, 5200 Auth Road, Camp Springs, MD 20746-
4304, Attn: 10th SATMET (fax: 301-763-8580; e-mail: satmet10@nesdis.noaa.gov).

Additional information will be regularly posted on the Web site: http://www.atmos.uah.edu/ lernr/satcom/ satcom.html. For registration, hotel and general information visit the AMS Web site at http://www.ametsoc.org/ AMS, e-mail (amsmtgs@ametsoc.org), or call the AMS Meetings Office (tel: 617-227-2426, ext. 226). (12/98; $\mathrm{r} 2 / 99 ; \mathrm{r} 3 / 99 ; \mathrm{r} 4 / 99 ; \mathrm{r} 7 / 99)$

\section{Ninth Symposium on Education, 9-14 January 2000, Long Beach, California}

The Ninth Symposium on Education, sponsored by the American Meteorological Society and organized by the AMS Board on School and Popular Meteorological and Oceanographic Education and the AMS Board on Meteorological and Oceanographic Education for Universities, will be held 9-14 January 2000 as part of the 80th AMS Annual Meeting in Long Beach, California. The theme of this year's symposium is "Atmospheric and Oceanographic Education-Expanding our Vision for the New Millennium."

The deadline for abstracts has passed. Papers were solicited on the following areas: $\mathrm{K}-12$ Educational Initiatives, University Educational Initiatives, Educational Outreach Activities and Public Awareness Activities on Weather, Climate and the Oceans. There will be two special sessions: a report on the results of the AMS demographic survey of the membership and educational applications of satellite meteorology and oceanography.

A preprint volume is planned and authors of accepted abstracts are encouraged to contribute to this volume. Instructions for formatting extended manuscripts for the preprint volume will be posted on the AMS Web site. Camera-ready manuscripts (page length to be determined), including photos and diagrams, must be submitted by 1 October 1999 to AMS Headquarters. Page charges will be assessed to defray printing costs. Registrants will receive a preprint volume at the conference.

For further information contact: David R. Smith, Oceanography Department, United States Naval Academy, Annapolis, MD 21402 (tel: 410-293-6553; fax: 410-2932137; e-mail: drsmith@nadn.navy.mil). Participants with additional suggestions for the program are encouraged to contact the program chairperson.

For registration, hotel and general information visit the AMS Web site at http://www.ametsoc.org/AMS, e-mail (amsmtgs@ametsoc.org), or call the AMS Meetings Office (tel: 617-227-2426, ext. 227). (12/98; 6/99)

\section{Fourth Symposium on Integrated Observing Systems, 9-14 January 2000, Long Beach, California}

The Fourth Symposium on Integraed Observing Systems, sponsored by the American Meteorological Society, 
will be held 9-14 January 2000 as part of the AMS Annual Meeting in Long Beach, California.

The symposium will include all aspects of the regional and global heterogeneous observing systems and the assimilation systems which are used to combine and use the data for various disciplines.

The deadline for abstracts has passed. Papers were solicited in the following areas: 1) New observing systems or sensors, 2) Advances in use of observational data, 3) Adaptive observations. The science and technology of intelligent choice of observing systems based on real-time data, 4) Role of observing systems in weather, climate, oceans, hydrology, chemistry etc., 5) Testing and simulation of observing systems; and 6) Assimilation. The field of assimilation of observations for use in numerical weather prediction is advancing rapidly. Papers in various techniques of assimilation, and its use in research and operations were encouraged. Participants with additional suggestions for the program are encouraged to contact the program chairperson.

A preprint volume is planned and authors of accepted abstracts are encouraged to contribute to this volume. Instructions for formatting extended manuscripts for the preprint volume will be posted on the AMS Web site. Camera-ready manuscripts (page length to be determined), including photos and diagrams, must be submitted by 1 October 1999 to AMS Headquarters. Page charges will be assessed to defray printing costs. Registrants will receive a preprint volume at the conference.

For further information contact Symposium Chairperson: Alexander MacDonald R/E/FS, NOAA/Forecast Systems Laboratory, 325 S. Broadway, Boulder, CO 80303 (tel: 303-497-6378; fax: 303-497-6821; e-mail: macdonald@ fsl.noaa.gov). For registration, hotel and general information visit the AMS Web site at http://www.ametsoc.org/ AMS, e-mail (amsmtgs@ametsoc.or), or call the AMS Meetings Office (tel: 617-227-2426, ext. 227). (12/98; r3/99; r7/99)

\section{Third Symposium on Fire and Forest Meteorology, 9-14 January 2000, Long Beach, California}

The Third Symposium on Fire and Forest Meteorology, sponsored by the American Meteorological Society, will be held 9-14 January 2000 in conjunction with the 80th AMS Annual Meeting in Long Beach, California.

The symposium is organized by the AMS Committee on Agricultural and Forest Meteorology. A joint session may be held with the Second Conference on Environmental Applications and/or with the 11th Joint Conference on the Applications of Air Pollution Meteorology with the Air and Waste Management Association.

The theme of the symposium will be to share experiences, new techniques and technologies and/or changes in the areas of 1) coupled fire-atmosphere modeling, 2) use of atmospheric model gridded data for short-range fire planning, including, but not limited to, application to the next generation fire danger rating system, 3) use of weather forecasts for prescribed fire planning and execution, 4) techniques in smoke management and air quality mitigation related to the new national fire policy and the EPA PM2.5 standards, 5) midand long-range forecasting for fire control and fire use planning, 6) operational and near-operational fire weather forecasting techniques-use of new technologies and resources, 7) weather applications for operational fire behaior assessment and forecasts. Participants with additional suggestions for the program are encouraged to contact the program chairperson.

The deadline for abstracts has passed. A preprint volume is planned and authors of accepted abstracts are encouraged to contribute to this volume. Instructions for formatting extended manuscripts for the preprint volume will be posted on the AMS Web site. Camera-ready manuscripts (page length to be determined), including photos and diagrams, must be submitted by 1 October 1999 to AMS Headquarters. Page charges will be assessed to defray printing costs. Registrants will receive the preprint volume at the conference.

For further program information contact either one of the program cochairpersons: David W. Goens, NWS, P.O. Box 9350, Missoula, MT 59803 (tel: 406-329-4715; fax: 406-329-4842; e-mail: david.goens@noaa.gov) or Sue Ferguson, Forestry Sciences Lab, 4043 Roosevelt Way NE, Seattle, WA 98105-6497 (tel: 206-553-7815; fax: 206-5537709; e-mail: ferguson@ dorothy.cfr.washington.edu). For registration information visit the AMS Web site at http:// www.ametsoc.org/AMS or call the AMS Meetings Office (tel: 617-227-2426, ext. 226). (1/99; r5/99; r7/99)

\section{Second Conference on Artificial Intelligence, 9- 14 January 2000, Long Beach, California}

The Second AMS Conference on Artificial Intelligence (AI), sponsored by the American Meteorological Society and organized by the AMS Committee on Artificial Intelligence, will be part of the 80th AMS Annual Meeting in 9-14 January 2000, Long Beach, California.

The purpose of the conference is to strengthen the interaction among researchers, research managers, technical experts, and potential users of artificial intelligence techniques as they are applied in meteorology and related sciences. Stimulating these relationships will foster progress within each community and in the use of AI in general. Relevant issues include (but are not limited to) the determination of the most appropriate uses of artificial intelligence, overall acceptance in the use of AI techniques, user perspectives, main streaming AI, and what lessons have been learned when applying AI techniques.

The deadline for abstracts has passed. Papers were solicited on the application of AI techniques to meteorology and related sciences and the issues related to such application. These techniques include knowledge base systems (expert systems, etc.), artificial neural networks, machine 
learning, knowledge discovery, data mining, case-based reasoning, computer vision, natural language processing, cognitive task analysis, decision support tools, and the use of fuzzy set theory (e.g, fuzzy logic).

A joint session with the 10th Conference on Satellite Meteorology and Oceanography will also be included in the conference program. This session will include an invited oral presentation and posters. These posters will provide the authors an opportunity for closer interaction among attendees of both conferences. Please see the satellite conference Call for Papers for additional details. Participants with additional suggestions for the program are encouraged to contact the program chairperson.

A preprint volume is planned and authors of accepted abstracts are encouraged to contribute to this volume. Instructions for formatting extended manuscripts for the preprint volume will be posted on the AMS Web site. Camera-ready manuscripts (page length to be determined), including photos and diagrams, must be submitted by 1 October 1999 to AMS Headquarters. Page charges will be assessed to defray printing costs. Registrants will receive the preprint volume at the conference. For further information contact Richard L. Bankert, Naval Research Laboratory, 7 Grace Hopper Ave., Monterey, CA 93943-5502 (tel: 831-656-4880, fax: 831-656-4769, e-mail: bankert@ nrlmry.navy.mil).

For registration, hotel and general information visit the AMS Web site at http://www.ametsoc.org/AMS, e-mail (amsmtgs@ametsoc.org), or call the AMS Meetings Office (tel: 617-227-2426, ext. 226). (12/98; r3/99; r7/99)

\section{Symposium on Atmospheric Chemistry Issues in the 21 st Century, 9-14 January 2000, Long Beach, California}

The Symposium on Atmospheric Chemistry Issues in the 21st Century, sponsored by the American Meteorological Society and organized by the AMS Committee on Atmospheric Chemistry, will be held 9-14 January 2000 as part of the 80th AMS Annual Meeting in Long Beach, California.

The 80th AMS Annual Meeting theme is "Applying Environmental Science to Societal Needs in the New Millennium." In keeping with that theme, this symposium will solicit both oral and poster presentations, and plan to have a number of joint sessions with other conferences/symposia, such as the Second Symposium on Environmental Applications, the 11th Joint Conference on the Applications of Air Pollution Meteorology with the Air and Waste Management Association, the 11th Symposium on Global Change Studies, the 11th Conference on Middle Atmosphere, and the Ninth Symposium on Education.

This symposium will address key issues that will need to be addressed by atmospheric chemists and meteorologists in the 21st Century in tropospheric and stratospheric chemistry. Fundamental aspects of atmospheric chemistry and its integration with urban-, regional-, and global-scale modeling and measurement will be addressed.

The deadline for abstracts has passed. Contributions within the general areas of atmospheric chemistry were welcomed. Specific topical areas were sought, including: 1) tropospheric aerosols-chemistry and radiative properties, 2) urban air chemistry in complex terrain, 3) air pollution impacts on the biosphere and carbon cycles, 4) aircraft and remote sensing of atmospheric trace gases and aerosols, 5) boundary layer nighttime chemical processes, 6) heterogeneous chemical reactions in clouds, 7) stratospheric heterogeneous chemistry and stratospheretroposphere exchange, 8 ) integration of measurement and modeling on urban and regional scales, 9) advances in instrumentation for aerosol and trace gas measurements, and 10) impacts of alternative fuels on air quality. Poster presentations from undergraduate and graduate students involved in atmospheric chemistry studies and internships were invited for the joint session with the Ninth Conference on Education. Participants with additional suggestions for the program are encouraged to contact the program chairperson.

A preprint volume is planned and authors of accepted abstracts are encouraged to contribute to this volume. Instructions for formatting extended manuscripts for the preprint volume will be posted on the AMS Web site. Camera-ready manuscripts (page length to be determined), including photos and diagrams, must be submitted by 1 October 1999 to AMS Headquarters. Page charges will be assessed to defray printing costs. Registrants will receive the preprintvolume at the conference.

For further information contact Jeffrey S. Gaffney, Argonne National Laboratory, Bldg. 203/ER, Argonne, IL 60439 (tel: 630-252-5178; fax: 630-252-7415; e-mail: gaffney@anl.gov). For hotel and general information visit the AMS Web site at http://www.ametsoc.org/AMS, e-mail (amsmtgs@ametsoc.org), or call the AMS Meetings Office (tel: 617-227-2426, ext. 305). (3/99; r7/99)

\section{Symposium on Lidar Atmospheric Monitoring, 9- 14 January 2000, Long Beach, California}

A Symposium on Lidar Atmospheric Monitoring, sponsored by the American Meteorological Society and organized by the AMS Committee on Laser Atmospheric Studies, will be held 9-14 January 2000 as part of the 80th AMS Annual Meeting in Long Beach, California.

Lidar probing of the atmosphere has progressed for more than 30 years, and in many respects the basic technologies have matured and their applications have emerged as viable long-term monitoring tools to aid in climate-related research. This symposium is intended to review the knowledge gained from long-term (multiyear to decadal) lidar observation programs involving clouds, aerosols, trace gases, and thermodynamic variables throughout the depth of the atmosphere. The meeting will consist of a 
number of invited review talks and contributed papers and posters.

Comprehending climate and climate change issues requires a proper characterization of current atmospheric conditions, and their monitoring to reveal trends in response to plausible climate forcings, for example, the crucial datasets of the increasing trends in carbon dioxide concentrations and surface air temperatures over historic times. The scope of this symposium is not on the lidar technologies that are currently contributing to this effort, but rather on their routine application to studying the state and composition of the atmosphere, including the clouds, aerosols, radiatively important gases, and thermodynamic structures of the troposphere, stratosphere, and mesosphere.

The deadline for abstracts has passed. Papers were also solicited for a joint session with the 11th Symposium on Global Change Studies for an overview of pertinent lidar probing techniques, and to highlight lidar findings of particular importance to climate research. There is increasing emphasis being given to acquiring long-term lidar datasets, but under what conditions can lidar remote sensing data records be used to discern climatological trends, and what are the signatures to search for? Participants with additional suggestions for the program are encouraged to contact the program chairperson.

A preprint volume is planned and authors of accepted abstracts are encouraged to contribute to this volume. Instructions for formatting extended manuscripts for the preprint volume will be posted on the AMS Web site. Camera-ready manuscripts (page length to be determined), including photos and diagrams, must be submitted by 1 October 1999 to AMS Headquarters. Page charges will be assessed to defray printing costs. Registrants will receive the preprint volume at the conference.

For further information contact: Kenneth Sassen, 135 S 1470 E, 819 WBB, University of Utah, Salt Lake City, UT 84112 (tel: 801-585-992; fax: 801-585-3681; e-mail: ksassen@atmos.met.utah.edu). For general information visit the AMS Web site at http://www.ametsoc.org/AMS, e-mail (amsmtgs@ametsoc.org), or call the AMS Meetings Office (tel: 617-227-2426, ext. 227). (12/98; r7/99)

\section{Symposium on The Mystery of Severe Storms: A Tribute to the Work of T. Theodore Fujita, 9- 14 January 2000, Long Beach, California}

A special symposium sponsored by the American Meteorological Society, The Mystery of Severe Storms: A Tribute to the Work of T. Theodore Fujita, will be held as part of the AMS 80th Annual Meeting in Long Beach, California, 9-14 January 2000.

The symposium will be organized by the AMS Committee on Severe Local Storms. Plans are to include both invited and solicited papers highlighting major areas of study pioneered by Dr. Fujita, including 1) mesoanalysis, 2) tornado genesis and climatology, 3) poststorm analysis of tornado damage, behavior and intensity, 4) microbursts and down bursts, and 5) a poster session is being planned on topics that have been addressed by Fujita. Sessions are being organized around the above topics, with each oral session consisting of two invited 45 minute presentations.

The symposium will also include one or more poster sessions of solicited papers on topics that have been addressed by Fujita. The deadline for abstracts has passed No preprint volume is planned, but the invited presentations may be published separately in the Bulletin.

For further information please contact the Program Chairperson, Gregory S. Forbes, Pennsylvania State University, College of Earth and Mineral Sciences, Department of Meteorology, 503 Walker Building, University Park, PA 16802 (tel: 814-863-2458; fax: 814-865-3663; e-mail: forbes@ems.psu.edu).(12/98; r5/99; r7/99)

\section{Symposium on Project VORTEX: What We Have Learned-Where We Must Go, 9-14 January 2000, Long Beach, California}

A special one-day Symposium on Project VORTEX (Verification of the Origins of Rotation in Tornadoes Experiment), sponsored by the American Meteorological Society and organized by the AMS Committee on Severe Local Storms, will be held as part of the AMS 80th Annual Meeting, 9-14 January 2000, in Long Beach, California.

The symposium will include primarily invited papers highlighting some of the more significant findings from VORTEX. Presentations will review current theories of tornado genesis, the influence of unobservable scales on the tornado development, recent trends in storm-scale modeling, and some of the challenges involved in discriminating between tornadic and nontornadic supercell storms. In support of the theme of the annual meeting, "Applying Environmental Science to Societal Needs in the Next Millennium," case studies and manuscripts on VORTEXrelated forecast and warning techniques, warning dissemination methods, and public preparedness issues are hereby solicited. The symposium will likely consist of four sessions, with an invited (30 minute) talk followed by four contributed (15 minute) presentations. There will be no poster sessions.

The deadline for abstracts has passed. For information contact: Erik Rasmussen, NSSL, N/C/MRD, 325 Broadway, Boulder, CO 80303 (tel: 303-497-6886; e-mail: rasm@ucar.edu).

For registration, hotel, and general information visit the AMS Web site at http://www.ametsoc.org/AMS, e-mail (amsmtgs@ ametsoc.org), or call the AMS Meetings Office (tel: 617-227-2426, ext. 226, 227, or 305). (12/98; r7/99) 
Second International Conference on Geospatial Information in Agriculture and Forestry, 1012 January 2000, Orlando, Florida

The Second International Conference on Geospatial Information in Agriculture and Forestry, organized by ERIM International, will be held 10-12 January 2000 at the Disney's Coronado Springs Resort in Orlando, Florida. The AMS is a cooperating organization.

This international meeting will focus on trends in the development and use of information technology products by the agricultural and forestry communities with special emphasis on applying advanced geospatial information techniques to improve today's management practices and decision support systems.

The technical program will offer over 300 general and interactive presentations, an extensive hands-on workshop program, demonstrations, and an exhibits program for products and services. Major topic areas will examine Data Collection and Analysis Tools, Geospatial Data Availability, Information Requirements and Technology Transfer, Forest Resource Assessments, Data Integration for Decision Support, GIS for Soil and Water Management, Natural Resources and Habitat Management, Crop Modeling and Information Technologies, Remote Sensing in Crop Production, and more.

The deadline for abstracts has passed. Extended, camera-ready manuscripts, to be published in the conference proceedings are due by 8 October 1999. For more information contact EI Conferences; P.O. Box 134008, Ann Arbor, MI 48113-4008 (tel: 734-994-1200 ext. 3350; fax: 734-994-5123; e-mail: dehring@erimint.com).

For registration, hotel, and general information visit the AMS Web site at http://www.ametsoc.org/AMS, e-mail (amsmtgs@ametsoc.org), or call the AMS Meetings Office (tel: 617-227-2426, ext. 226, 227, or 305). (4/99; 6/99)

\section{Conference on European Tornadoes and Severe Storms, 1-4 February 2000, Toulouse, France}

The Observatoire Midi-Pyrénées and Météo-France will hold a Conference on European Tornadoes and Severe Storms from 1-4 February 2000, in Toulouse, France. United States cosponsors include NOAA, National Severe Storms Laboratory, the College of Geosciences at the University of Oklahoma, and the Wind Science and Engineering Program t Texas Tech University. The American Meteorological Society is a cooperating organization.

Topics to be addressed at the conference include 1) The climatology-modern and historic-of all aspects of severe thunderstorms in Europe; 2) Severe wind phenomena produced by thunderstorms, including both damaging straightline winds and tornadoes; 3) Hail, heavy precipitation, and electrical phenomena produced by thunderstorms and related mesoscale systems; 4) Synoptic and mesoscale processes associated with deep convection; 5) Numerical modelling of severe storms and rotating cloud systems; and 6) Forecasting of severe thunderstorms and tornadoes.
The deadline for abstracts has passed. Individuals intending to participate in this conference, whether presenting a paper or not, are invited to contact one of the conveners to receive registration materials. Participation must be confirmed in September 1999 by sending a completed registration form and the registration fee.

Additional information is available at the conference Web site at http://www.eurotornado.ou.edu. The conveners are Jean Dessens, Laboratoire d'Aérologie, Observatoire Midi-Pyrénées, Centre de Recherches Atmosphériques, 65300 Campistrous, France (e-mail: desj@aero.obs-mip.fr); Gérard De Moor, CNRM, Météo-France, 42 avenue Gaspard Coriolis, 31057 Toulouse Cedex 01, France (e-mail: gerard.demoor@meteo.fr); and John T. Snow, College of Geosciences, University of Oklahoma, Sarkeys Energy Center, Room 710, 100 East Boyd Street, Norman, OK 73019-1008 (e-mail: jsnow@ou.edu). (4/99; r5/99; 8/99)

\section{Ninth Workshop on Technical and Scientific Aspects of MST Radar, 13-17 March 2000, Toulouse, France}

The Ninth Workshop on Technical and Scientific Aspects of MST Radar, sponsored by the Koninklijk Nederlands Meteorologisch Instituut (KNMI), will be held 13-17 March 2000 in Toulouse, France. The American Meteorological Society is a cooperating organization. This workshop will be combined with the final COST-76 Workshop on Utilization of UHF/VHF Radar Windprofiler Networks.

For further information contact: Juergen Roettger (e-mail:roettger@linmpi.mpg.de), Vladislav Klaus (e-mail: vladislav.KLAUS@meteo.fr), or Wim A. Monna (e-mail: monna@knmi.nl). (5/99)

\section{0th Anniversary Meeting of the Royal Meteo- rological Society, 3-4 April 2000, London, United Kingdom}

To mark the 150th anniversary of the Society's foundation, a this two-day meeting will be held at the Royal Society of London. This meeting will cover the history of the Society, its antecedents, its contemporaries and the societies with whom it has shared many interests and members, namely the Royal Society, the Scottish Meteorological Society, the British Rainfall Organization, the Royal Astronomical Society, the Royal Geographical Society and the Institution of Civil Engineers.

Further information e-mail the Royal Meteorological Society (e-mail: execsec@ royal-met-soc.org.uk), Anita McConnell (e-mail: amcconnell@oup.co.uk), or J. M. Walker (e-mail: wakerjm@btinternet.com). (5/99)

\section{Sixth International Conference on Southern Hemisphere Meteorology and Oceanography, 3- 7 April 2000, Santiago, Chile}

The Sixth International Conference on Southern Hemisphere Meteorology and Oceanography (6 ICSHMO), spon- 
sored by the American Meteorological Society and the University of Chile (UCH) will be held 3-7 April 2000, at the Diego Portales Convention Center, located in downtown Santiago, Chile.

This meeting is cosponsored by the World Meteorological Organization (WMO), the National Science Foundation (NSF), National Oceanic and Atmospheric Administration (NOAA), National Aeronautics and Space Administration (NASA) and the following institutions and organizations in Chile: National Commission on Science and Technology (CONICYT), University of Concepcion (UdeC), Chilean Bureau of Meteorology (DMC), National Oceanographic Committee (CONA), Water Resources Authority (DGAMOP), and Chilean Antarctic Institute (INACH).

The central theme of this conference is "Water Resources and Their Management: Focus on the Southern Hemisphere."

The deadline for abstracts has passed. Papers were solicited on all aspects of Southern Hemisphere ( $\mathrm{SH}$ ) meteorology and oceanography of general interest. Special attention was given to the following topics as they related to the main theme of the conference: 1) weather forecasts and climate prediction with lead times from intraseasonal to interannual, 2) tropical-extratropical interactions and teleconnections in the $\mathrm{SH}, 3$ ) decadal, ENSO and intraseasonal oscillations in the $\mathrm{SH}, 4$ ) ocean-atmosphere-land interactions, 5) SH monsoon systems, 6) regional climate and hydrologic applications, 7) oceanography of the southern oceans and eastern boundary currents; and 8) antarctic meteorology and climatology. The central theme will be emphasized, but papers related to other aspects of SHMO are welcome. Participants with additional suggestions for the program are encouraged to contact the chairperson.

A preprint volume is planned and authors of accepted abstracts are encouraged to contribute to this volume. Instructions for formatting extended manuscripts for the preprint volume will be posted on the AMS Web site. Camera-ready manuscripts (page length to be determined), including photos and diagrams, must be submitted by 30 December 1999 to AMS Headquarters. Page charges will be assessed to defray printing costs. Registrants will receive the preprint volume at the conference.

Some limited travel funds are available from the NSF/ NOAA/NASA for students and post doctors, and from other sources for participants from developing countries. The application form and procedures are listed on SHMOWeb page (see below for address) and the AMS Home page (http://www.ametsoc.org/AMS).

For further information, contact either one of the Program Chairpersons: Patricio Aceituno, Dept. of Geophysic, University of Chile, asilla 2777, Santiago, Postal Code 6511227, Chile (e-mail: Aceituno@SHMO-Chile2000.cl), Kingtse Mo, NCEP/CPC, 5200 Auth Rd., Camp Springs, MD 20746 (e-mail: kmo@ncep.noaa.gov), or visit Web site http://www.SHMO-Chile2000.cl. (12/98; r1/99; r4/99; r9/99)

\section{Short Course on Climate-Change Detection, 7 May 2000, Asheville, North Carolina}

An AMS Short Course on Climate-Change Detection, sponsored by the American Meteorological Society, will be held on Sunday, 7 May 2000, preceding the 15th Conference on Probability and Statistics in the Atmospheric Sciences, and the 12th Conference on Applied Climatology in Asheville, North Carolina.

This half-day short course will be instructed by Francis Zwiers, of the Canadian Centre for Climate Modelling and Analysis. The topics covered provisionally include 1) Basic ideas on optimal signal detection, 2) Detection and attribution paradigm, 3) Detection is regression, 4) Dimension reduction, 5) Attribution consistency test, 6) Some variations on optimal detection, 7) Non-optimal pattern similarity measure; and 8) Summary and review. Familiarity with basic matrix algebra will be assumed.

For further information contact either Dan Wilks (dsw5@cornell.edu) or Art Degaetano (atd2@cornell.edu), Department of Soil, Crop and Atmospheric Sciences, Bradfield Hall, Cornell University, Ithaca, NY 14853 (8/99)

\section{Call for Papers}

\section{5th Conference on Probability and Statistics in the Atmospheric Sciences, 8-1 1 May 2000, Asheville, North Carolina}

The 15th Conference on Probability and Statistics in the Atmospheric Sciences, sponsored by the American Meteorological Society and organized by the AMS Committee Probability and Statistics, will be held 8-11 May 2000, in Asheville, North Carolina. This meeting will be held in conjunction with the 12th Conference on Applied Climatology, and will include joint sessions with that conference.

Papers are solicited on all aspects of Probability and Statistics as they relate tothe Atmospheric Sciences, including but not limited to ensemble forecasting; other statistical forecasting approaches; forecast verification and forecast value; probability and statistics in remote sensing; time series; spatial statistics; and space-time modeling. Contributions suitable for joint sessions with the 12th Conference on Applied Climatology, for example in areas such as extreme-value analyses, uses of probability and statistics in applied climatological problems, and novel probabilistic climate applications (e.g., "weather derivatives"), are particularly encouraged. Participants with additional suggestions for the program are encouraged to contact the program chairperson.

The deadline for receipt of abstracts is 20 December 1999. Abstracts are now submitted electronically (visit the AMS Web site at http://www.ametsoc.org/AMS or refer page 1951 of the Bulletin for instructions on this new electronic procedure). The preliminary program will be published on the AMS Web site in January of 2000. 
A preprint volume is planned and authors of accepted abstracts are encouraged to contribute to this volume. Instructions for formatting extended manuscripts for the preprint volume will be posted on the AMS Web site. Complete, camera-ready manuscripts (page length to be determined) must be submitted no later than 14 February 2000 to AMS Headquarters. Page charges and any additional charges for photo processing will be assessed to defray printing costs. Registrants will receive the preprint volume at the conference. For further information contact: Dan Wilks, 1113 Bradfield Hall, Cornell University, Ithaca NY 14853 (tel: 607-255-1750; fax: 607-255-2106; e-mail: dsw5@cornell.edu). (4/99; r5/99)

\section{Call for Papers}

\section{2th Conference on Applied Climatology, 8- 11 May 2000, Asheville, North Carolina}

The 12th Conference on Applied Climatology, sponsored by the American Meteorological Society and organized by the Committee on Applied Climatology, will be held 8-11 May 2000, in Asheville, North Carolina. This meeting will be held in conjunction with the 15 th Conference on Probability and Statistics in the Atmospheric Sciences.

Papers are solicited on all aspects of applied climatology. In particular, papers dealing with climate impacts, applications and extremes are desired as are those addressing the integration of federal and nonfederal climate networks to solve applied climate problems.

Several joint sessions with the 15 th Conference on Probability and Statistics are planned. Submissions focusing on extreme-value analyses, novel applications of statistics to applied climatological problems and probablistic climate applications (e.g. weather derivatives) are encouraged. Participants with additional suggestions for the program are encouraged to contact the program chairperson.

The deadline for abstracts is 20 December 1999. Abstracts are now submitted electronically (visit the AMS Web site at http://www.ametsoc.org/AMS or refer page 1951 of the Bulletin for instructions on this new electroni procedure). The preliminary program will be published on the AMS Web site in January of 2000.

A preprint volume is planned and authors of accepted abstracts are encouraged to contribute to this volume. Instructions for formatting extended manuscripts for the preprint volume will be posted on the AMS Web site. Complete, camera-ready manuscripts (page length to be determined) must be submitted no later than 14 February 2000 to AMS Headquarters. Page charges and any additional charges for photo processing will be assessed to defray printing costs. Registrants will receive the preprint volume at the conference.

For information please contact: Program Chairperson, Art DeGaetano (tel: 607-255-0385; fax: 607-255-2106; e-mail: atd2@cornell.edu). (4/99; r5/99)

\section{Call for Papers}

\section{Millennium NATO/CCMS International Technical Meeting on Air Pollution Modelling and Its Application, 15-19 May 2000, Boulder, Colorado}

The Millennium NATO/CCMS International Technical Meeting on Air Pollution Modelling and Its Application (formerly published as the 24th International Technical Meeting on Air Pollution Modeling and Its Application) will he held 15-19 May 2000 in Boulder, Colorado. The American Meteorological Society is a cooperating organization.

At this ITM the following key topics will be distinguished: 1) Role of Atmospheric Models in Air Pollution Policy and Abatement Strategies; 2) Integrated Regional Modelling (local effects, mesoscale phenomena, regional modelling, one and two way nesting, application of existing models); 3) Global and Long-Range Transport (synoptic, hemispheric and global scales, application of existing models); 4) Regional Air Pollution and Climate (dispersion of climate-sensitive regional contaminants in climate models; direct and indirect climate effects of aerosols and tropospheric ozone); 5) New Developments (microscale to global scale, new models, new extensions to existing models); and 6) Model Assessment and Verification (model verification, agreement and/or discrepancy of model results compared to measurements, design of field experiments, use of on-site meteorological data, limits to predictability).

The meeting will consist mainly of oral presentations but posters will also be accepted. Intention to offer a presentation or poster must be received together with an abstract (one-half to 1 page in length) containing essential information and designation of key topic no later than 1 September 1999 to Sven-Erik Gryning, Wind Energy and Atmospheric Physics Dept., Ris $\varnothing$ National Lab, DK4000 Roskilde, Denmark (e-mail: Sven-Erik.Gryning@ risoe.dk).

For meeting information, contact Sven-Erik Grying at the above address or Francis A. Schiermeier, Atmospheric Sciences Modeling Division, U.S. EPA/NOAA (MD-80), Research Triangle Park, NC 27711 (tel: 919-541-4542; e-mail: francis.schiermeier@noaa.gov). Additional information will be published in future issues of the Bulletin. $(2 / 99 ; r 5 / 99)$

\section{Call for Papers}

\section{4th Conference on Hurricanes and Tropical Meteorology, 29 May-2 June 2000, Ft. Lauderdale, Florida}

The 24th Conference on Hurricanes and Tropical Meteorology, organized by the AMS Committee on Tropical Meteorology and Tropical Cyclones and sponsored by the American Meteorological Society, will be held 29 May2 June 2000, at the Greater Fort Lauderdale/Broward County Convention Center in Fort Lauderdale, Florida, in 
conjunction with the AMS 10th Conference on Interaction of the Sea and Atmosphere.

Both poster and oral presentations on all aspects of tropical cyclones and tropical meteorology are to be encouraged. Sessions on the results from the CAMEX, SCSMEX, TIPEX, GAME, and USWRP Hurricanes-at-landfall field programs along with work on the reanalysis of historical hurricane activity are being considered. Joint sessions with the interactions of the sea and atmosphere conference (Richard W. Reynolds, chairperson) are likely to include 1) tropical atmosphere-ocean seasonal predictability; 2) influence of air-sea interactions on monsoon development, variability and predictability; and 3) ocean interaction effects on tropical cyclone intensity. Participants with additional suggestions for special/joint sessions are encouraged to contact the program chairperson.

Deadline for abstracts is 1 November 1999. Abstracts are now submitted electronically (visit the AMS Web site at http://www.ametsoc.org/AMS or refer page 1951 of the Bulletin or instructions on this new electronic procedure). A preprint volume is planned and authors of accepted abstracts are encouraged to contribute to this volume. Instructions for formatting extended manuscripts for the preprint volume will be posted on the AMS Web site. Camera-ready manuscripts (page length to be determined), including photos and diagrams, must be submitted by 15 March 2000 to AMS Headquarters. Page charges will be assessed to defray printing costs. Registrants will receive the preprint volume at the conference.

The Max A. Eaton Prize will be awarded at this conference for the best student paper. The paper will be judged on content and presentation by a panel selected by the conference program committee. Entrants must be currently enrolled in high school, college, or graduate school. Students who have just completed a degree but have not begun regular employment at the time of the conference are also eligible. The prize, a monetary award plus a certificate, was established to recognize Max A. Eaton's lifelong contributions to tropical meteorology and the encouragement he gave to so many young researchers.

For further program information, contact Chris Landsea (tel: 305-361-4357; fax: 305-361-4402; e-mail: landsea@ aoml.noaa.gov). (4/99; r6/99)

\section{Gall for Papers}

\section{0th Conference on Interaction of the Sea and At- mosphere, 29 May-2 June, Ft. Lauderdale, Florida}

The 10th Conference on Interaction of the Sea and Atmosphere, sponsored by the AMS and organized by the AMS Committee on the Sea and Atmosphere, will take place at the Greater Fort Lauderdale/Broward County Convention Center from 29 May-2 June 2000 in Fort Lauderdale, Florida. This conference will be held in conjunction with the 24th Conference on Hurricanes and Tropical Meteorology.
The conference will address air-sea interactions on multiple scales. Results of observational and modeling studies are of interest. Papers are solicited on all aspects of interactions of the sea and atmosphere. Planned sessions are 1) predictability of the tropical atmosphere-ocean system on seasonal timescales; 2 ) influence of air-sea interactions on monsoon development, variability and predictability; 3) ocean interaction effects on tropical cyclone intensity; 4) air-sea interactions in the warm water pool in the eastern Indian Ocean and western Pacific Ocean; 5) air-sea interactions and the North Atlantic Oscillation; 6) air-sea interaction and Pacific Decadal Variability; 7) simulations of oceanographic and atmospheric variables from coupled ocean-atmosphere general circulation models; 8) coupled ocean-atmosphere boundary layer phenomena; 9) influence of freshwater flux and salinity on sea surface temperatures and ocean dynamics; 10) parameterization of subgrid-size scale air-sea interactions in general circulation models; 11) instrumentation and methods. Joint sessions with the 24th Conference on Hurricanes and Tropical Meteorology (Chris Landsea, chairperson) are likely to include items 1-3. Participants with additional suggestions are welcome to contact the program chairperson.

Deadline for abstracts is 1 November 1999. Abstracts are now submitted electronically (visit the AMS Web site at http://www.ametsoc.org/AMS or refer page 1951 of the Bulletin or instructions on this new electronic procedure). A preprint volume is planned and authors of accepted abstracts are encouraged to contribute to this volume. Instructions for formatting extended manuscripts for the preprint volume will be posted on the AMS Web site. Camera-ready manuscripts (page length to be determined), including photos and diagrams, must be submitted by 15 March 2000 to AMS Headquarters. Page charges will be assessed to defray printing costs. Registrants will receive the preprint volume at the conference.

For further information, contact the Program Chairperson, Richard W. Reynolds, Climate Modeling Branch W/ NP24, NCEP/NWS/NOAA, 5200 Auth Road, Room 807, Camp Springs, MD 20746 (tel: 301-763-8000, ext 7580; fax: 301-763-8125; e-mail: rreynolds@ncep.noaa.gov). $(4 / 99 ; \mathrm{r} 6 / 99)$

\section{Call for Papers}

\section{Fourth International Symposium on Gas Transfer at Water Surfaces, 5-8 June 2000, Miami Beach, Florida}

The Fourth International Symposium on Gas Transfer at Water Surfaces will be held in Miami Beach, Florida. The American Meteorological Society is a cooperating organization.

This symposium is the fourth in a sequence of symposia on gas transfer at water surfaces. The first symposium was held at Cornell University in 1983, the second at the 
University of Minnesota, Minneapolis in 1990 and the third at the University of Heidelberg in 1995. The organizers feel that the increased interest in gas transfer as well as current and expected progress in experimental techniques and theoretical understanding makes a fourth symposium in $2000 \mathrm{a}$ very valuable event.

The fourth symposium will focus on a deeper understanding of gas transfer in natural systems: air-sea gas transfer and re-aeration of rivers and lakes. Papers are solicited on the following subjects: 1) Physical and Chemical Mechanisms Remote Sensing, 2) Innovative Measuring Technology, 3) Laboratory Measurements, 4) Modelling Biogeochemical Cycles; and 5) Field Measurements.

Please send your 1 page abstract by 1 February 2000. Refer to the conference Web site for further information $\mathrm{http}: / /$ cheyenne.rsmas.miami.edu/gas2000.html or contact: Gayl Van De Bogart, University of Miami, Rosenstiel School of Marine and Atmospheric Science, Division of Applied Marine Physics, 4600 Rickenbacker Causeway, Miami, FL 33149 (tel: 305-361-4972; fax: 305-361-4701; e-mail: gas2000@rsmas.miami.edu). (8/99)

\section{Preliminary Announcement}

\section{AMS Workshop on Basic Steps of Building a Forecast, 19 June 2000, San Francisco, California}

The AMS workshop, entitled, "Basic Steps of Building a Forecast," sponsored by the AMS and organized by the AMS Board of Broadcast Meteorology, will be held on 19 June 2000 at the Cathedral Hill Hotel in San Francisco, California. This workshop will precede the AMS 29th Conference on Broadcast Meteorology. Further details will appear in a future issue of the Bulletin.

For further information contact the program chairperson: Sterling Poulson, KUTV-TV, 2185 S. 3600 W, Salt Lake City, UT 84119 (e-mail: wxwindow @ burgoyne.com). (6/99)

\section{Call for Papers}

29th Conference on Broadcast Meteorology, 2024 June 2000, San Francico, California

The 29th Conference on Broadcast Meteorology, sponsored by the American Meteorological Society and organized by the AMS Board of Broadcast Meteorology, will be held 20-24 June 2000 at the Cathedral Hill Hotel in San Francisco, California. An AMS Workshop entitled "Basic Steps of Building a Forecast," will precede the conference.

The theme of this conference will be "Information and Data, Over-loaded or Under-used." Our goal is to bring the focus of the Broadcast Meteorologist back to the science of forecasting, and providing some tools to survive the increasing demands of television as well as the increasing demands of the science. The conference sessions will focus on several areas, including 1) The evolution of data gathering in the 20th century; 2) How to transition from 1950 s technology to the use of the satellites in upper-air analysis of the future; 3) Forecasting for television. Ego or science; 4) Using graphic displays of the models on air for localized forecasting. "Futurecasting," gimmick or science; 5) Dealing with the new "news" philosophy of "Local, Local, Local"; and 6) Weather disasters of the 90s teach us to prepare for the future. In addition, we will focus on the intricate connection of the ocean to our weather, with a special emphasis on marine weather in the local area of San Francisco.

Abstracts must be submitted to the program chairperson no later than 1 January 2000. Abstracts are now submitted electronically (visit AMS Web site at http:// www.ametsoc.org/AMS or refer page 1951 of the Bulletin or instructions on this new electronic procedure). Please submit your abstract on or before the deadline date. Papers will not be accepted after the abstract deadline.

The conference is chaired by Sterling Poulson, KUTVTV, 2185 S. 3600 W, Salt Lake City, UT 84119 (tel: 801973-3010; fax: 801-973-3349) with assistance from Dave Miller, WFRV-TV, Green Bay, WI 54301 (tel: 920-4375411 ext. 13241; fax: 920-437-4576) and Mike McClellan, WMBD-TV, 3131 N. University, Peoria, IL 61604 (tel: 309-686-8657).

For further information contact the program chairperson, Sterling Poulson at the address above. Participants with additional suggestions for the programs are encouraged to contact the program chairperson. $(4 / 99 ; \mathrm{r} 6 / 99)$

\section{Call for Papers}

\section{IUTAM Symposium on Advances in Mathematical Modelling of Atmosphere and Ocean Dynamics, 2- 7 July 2000 Limerick, Ireland}

A IUTAM (International Union of Theoretical and Applied Mechanics) Symposium on Advances in Mathematical Modelling of Atmosphere and Ocean Dynamics will take place at the University of Limerick, Ireland from 2-7 July 2000. It is being organized by the National Committee for Theoretical and Applied Mechanics of the Royal Irish Academy and is co-sponsoed by the National Committee for Geodesy and Geophysics and the International Union of Geodesy and Geophysics. The American Meteorological Society is a cooperating organization.

The goals of the symposium are to highlight advances in modelling of atmosphere and ocean dynamics, to provide a forum where atmosphere and ocean scientists can present their latest research results, and to facilitate interaction between theory and applications in atmosphere/ocean dynamics.

The symposium aims to bring together mathematical modellers and theoreticians from atmospheric science, oceanography and climatology to present advances in modelling and theory in these areas. To this end the symposium will address the following topics: 1) theory and simulation 
of global atmospheric and ocean flows; 2) approximations and simplifications of the dynamical equations; 3 ) coupled atmosphere-ocean models; 4) climate modelling on regional and global scales; 5) advances numerical methods for geophysical fluid dynamics; 6) variability of the atmosphere and ocean at different time scales; 7) nonlinear processes and predictability.

Scientists wishing to present a paper should send a 300 500 word abstract to the symposium secretariat by 15 December 1999. Authors will be notified of acceptance by 1 March 2000 . Full papers are due at the time of the symposium and they will appear (subject to positive review by the Scientific Committee) in the symposium proceedings due for publication, soon afterward.

For further information contact, P. F. Hodnett, University of Limerick, Chairman, Organising Committee (e-mail: IUTAMLIM@UL.IE). The symposium Web site for updated information is at: http://www.ul.ie/ iutamlim/. (8/99)

\section{Conference on Meteorology at the Millennium, 10- 14 July 2000, Cambridge, Berkshire, United Kingdom}

To celebrate the new century and the 150th birthday of the Royal Meteorological Society, a Conference on the Meteorology at the Millennium is being held from 1014 July 2000 at St. John's College, Cambridge, United Kingdom. The American Meteorological Society is a cooperating organization.

Meteorology is now at the forefront of science. It has provided the stimuli for new developments in several areas. For example, the study of chaotic systems began with the problems of weather prediction. At the same time, advancing knowledge in other science has led to new and exciting changes in the atmospheric sciences. One example is the newly appreciated two-way interaction between living things and their environment, including climate. No less important has been the advance of technology, which has given new tools and methods of analysis to the atmospheric sciences, and opened up new questions for scientific study. Developments in computing, space technology, and radar have all played central roles in developing, and have themselves been advanced by the modern science of meteorology.

This conference will explore the above interactions, reflecting on the way in which modern meteorology is contributing to the developments in other sciences and on the way in which atmospheric scientists are learning from their colleagues in other disciplines. Presentations will also reflect on the wider implications of these advances for society.

The conference will be planned around invited lectures from a wide cross-section of leading international speakers. At the same time there will be the opportunity to present contributed papers and posters. For further information contact the Royal Meteorological Society, 104 Oxford Rd., Reading, RG1 7LL, UK (tel: 440118956 8500; fax: 440118 956 8571; e-mail: execsec@ royal-met-soc.org.uk). 12/98)
Fourth International Conference on Hydroinformatics, 23-27 July 2000, lowa City, lowa

Fourth International Conference on Hydroinformatics (Hydroinformatics 2000), sponsored by the International Association of Hydraulic Research (IAHR), will be held 23-27 July 2000 in Iowa City, Iowa. The conference is hosted by the University of Iowa's College of Engineering Institute of Hydraulic Research. The American Meteorological Society is a cooperating organization.

Hydroinformatics, the application of modern information technologies to a wide range of problems in hydraulics and water resources, is an area of significant research and development. Drawing upon the latest in information technologies, hydroinformatics is paving the way for many new methodologies in planning, design, and decision making. Some of these methodologies have already offered novel solutions and tools for managing a number of challenges in our aquatic environment. The objective of Hydroinformatics 2000 is to bring together engineers, scientists, and practitioners with a common interest in these methodologies. The conference will provide a forum for exchange of ideas and experiences.

Conference topics will include numerical engines; decision support and management systems; integration of technologies; Geographic Information Systems (GIS); tools, environments and languages; data modeling and management; neural networks in hydroinformatics; evolutionary algorithms in hydroinformatics; internet, intranets and extranets; inverse modeling and data assimilation; uncertainty; ecology and water quality modeling; and experiences with modeling systems. For further information contact: 2000 Hydroinformatics 2000, Iowa Institute of Hydraulic Research, University of Iowa, 404 Hydraulics Lab., Iowa City, IA 52242-1585 (tel: 319-3355239; fax: 319-335-5238; e-mail: iihr@uiowa.edu; Web: http://www.iihr.uiowa.edu). (3/99)

\section{Call for Papers}

\section{4th Symposium on Boundary Layers and Turbulence, 7-1 1 August 2000, Aspen, Colorado}

The AMS 14th Symposium on Boundary Layers and Turbulence, sponsored by the American Meteorological Society and organized by the AMS Committee on Boundary Layers and Turbulence, will be held, in conjunction with the AMS Ninth Conference on Mountain Meteorology, 711 August 2000 at Snowmass Village in Aspen, Colorado. Papers will be considered on all aspects of boundary layer meteorology, oceanography, and basic turbulence research. Sessions will be organized by topic studied rather than methodology used. Topics of particula interest are convective boundary layers (BLs), stable BLs, marine and oceanic BLs, polar BLs, cloudy BLs, vegetative canopies, dispersion, and entrainment. Joint sessions with the Mountain Meteorology Conference are planned concerning flow over 
complex terrain. Papers of an interdisciplinary nature are also strongly encouraged.

The deadline for abstracts is $\mathbf{1 5}$ February 2000. Abstracts are now submitted electronically (visit the AMS Web site at http://www.ametsoc.org/AMS or refer page 1951 of the Bulletin or instructions on this new electronic procedure). As abstracts will be the basis of acceptance or rejection, authors are encouraged to be very specific in describing the content of their proposed papers.

A preprint volume is planned and authors of accepted abstracts are encouraged to contribute to this volume. Instructions for formatting extended manuscripts for the preprint volume will be posted on the AMS Web site. Camera-ready manuscripts (page length to be determined), including photos and diagrams, must be submitted by 15 May 2000 to AMS Headquarters. Page charges will be assessed to defray printing costs. Registrants will receive the preprint volume at the conference.

Awards for outstanding student presentations will be given. For further information about the symposium, visit the AMS web site or contact either one of the committee/ program cochairpersons: Steven Oncley (tel:303-4978757, e-mail: oncley@ucar.edu) or Jielun Sun (tel: 303497-8994; e-mail: jsun@ucar.edu), National Center for Atmospheric Research, P.O. Box 3000, Boulder, CO 80307-3000. (8/99)

\section{Call for Papers}

\section{Ninth Conference on Mountain Meteorology, 7- 11 August 2000, Aspen, Colorado}

The Ninth Conference on Mountain Meteorology, sponsored by the American Meteorological Society and organized by the AMS Committee on Mountain Meteorology, will be held 7-11 August 2000 at Snowmass Village in Aspen, Colorado, in conjunction with the AMS 14th Symposium on Boundary Layers and Turbulence.

The Mountain Meteorology Conference has established a tradition of providing an interdisciplinary forum for discussing the influence of mountains on the atmosphere on a wide range of spatial and temporal scales. Authors are invited to submit theoretical, observational and modeling papers in all areas of mountain meteorology, including the role of mountains in climate and the general circulation, lee cyclogenesis, terrain-induced waves, wakes, and instabilities, gap flows, orographic clouds and precipitation, topographically trapped disturbances, hydroclimatology and climatic changes in mountainous regions. In view of the collocation with the Symposium on Boundary Layers and Turbulence joint sessions on boundary layers, air quality, mixing and diffusion in complex terrain are planned. Special sessions will be devoted to the Mesoscale Alpine Project.

The deadline for abstracts is $\mathbf{1 5}$ February 2000. Abstracts should be submitted electronically (for instructions refer to the AMS web site at http://www.ametsoc.org/
AMS). Authors of accepted abstracts will be notified by 7 April 2000. A preprint volume is planned and authors of accepted abstracts are encouraged to contribute to this volume. Instructions for formatting extended manuscripts for the preprint volume will be posted on the AMS Web site. Camera-ready manuscripts (page length to be determined), including photos and diagrams, must be submitted by 15 May 2000 to AMS Headquarters. Page charges will be assessed to defray printing costs. Registrants will receive the preprint volume at the conference. Student papers will be eligible for the best student paper awards, which will be awarded at the end of conference.

For further information contact the program chair: Vanda Grubisic, Desert Research Institute, 2215 Raggio Pkwy, Reno, NV 89512-1095, (tel:775-674-7031, fax: 775674-7016, e-mail: grubisic@dri.edu). (8/99)

\section{Call for Papers}

\section{4th Conference on Agricultural and Forest Meteorology, 14-18 August 2000, Davis, California}

The 24th Conference on Agricultural and Forest Meteorology sponsored by the American Meteorological Society and organized by the AMS Committee on Agricultural and Forest Meteorology, will be held 14-18 August 2000 at the University of California, Davis, California. The conference will be held concurrently with the AMS 14th Conference on Biometeorology and Aerobiology and the AMS Third Symposium on the Urban Environment.

Contributions are solicited on all topics related to agricultural and forest meteorology, and to those related to meteorological aspects of other natural ecosystems. Appropriate topics include but are not limited to theoretical and applied studies of interactions between the atmosphere and the land surface; evapotranspiration and the energy balance; modeling and measurement of meteorological processes related to agriculture and forestry; canopy micrometeorology; weather data networks and requirements; and effects of weather and climate on agriculture and forestry.

Presentations will be either oral or poster. Prizes will be given to the best student papers, oral and poster. There will be opportunities for sessions on special topics such as "flux observations in non-ideal conditions." Proposals for other such sessions or for panel discussions are welcome. Participants with additional suggestions for the programs are encouraged to contact the program chairperson.

The deadline for abstracts is 21 February 2000. Abstracts are now submitted electronically (visit the AMS Web site at http://www.ametsoc.org/AMS or refer page 1951 of the Bulletin or instructions on this new electronic procedure). Authors of accepted abstracts will be notified by early May 2000. A preprint volume is planned and authors of accepted abstracts are encouraged to contribute to this volume. Instructions for formatting extended manuscripts for 
the preprint volume will be posted on the AMS Web site. Camera-ready manuscripts (page length to be determined), including photos and diagrams, must be submitted by 26 May 2000 to AMS Headquarters. Page charges will be assessed to defray printing costs. Registrants will receive the preprit volume at the conference.

For additional information, please contact the Program Chair: Professor Roger H. Shaw (rhshaw@ucdavis.edu), Department of Land, Air and Water Resources, One Shields Avenue, Davis, CA 95616-8627 (tel: 530-752-1822; fax: 530- 752-1552). (7/99; r8/99)

\section{Call for Papers}

\section{The 14th Conference on Biometeorology and Aero- biology, 14-18 August 2000, Davis, California}

The 14th Conference on Biometeorology and Aerobiology, sponsored by the American Meteorology Society and organized by the AMS Committee on Biometeorology and Aerobiology, will be held 14-18 August 2000, at University of California, Davis, California. The conference will be held concurrently with the 24th Conference on Agricultural and Forest Meteorology and the Third Symposium on the Urban Environment.

Papers on topics related to human biometeorology, vegetation biometeorology, urban biometeorology, and aerobiology are invited. The program will include oral and poster sessions. Joint sessions with the Third Symposium on the Urban Environment and the 24th Conference on Agricultural and Forest Meteorology are anticipated. Scientists who would like to organize symposia or sessions on related topics should contact the program organizers prior to the abstract deadline.

Papers and posters in traditional areas of human biometeorology are welcome. These include 1) weather and climate relationships with mortality and morbidity, including heat- and cold-wave mortality and seasonal variations; 2) respiratory disease associations, especially allergies; 3) empirical studies associating nonsevere weather and various physiological and psychological responses, including medical-meteorological forecasting; and 4) international studies of human biometeorology.

Papers and posters contributions are solicited on topics related to vegetation biometeorology. Appropriate topical areas include 1) microclimatic conditions in the vegetative canopy and their effect on vegetation processes; 2) effects of increasing carbon dioxide and other trace gas concentrations on vegetative growth and development; 3 ) effects of weather and climate extremes on physiological processes in vegetation. Sessions on suitable topics will be jointly sponsored with Conference on Agricultural and Forest Meteorology.

The aerobiology sessions will have two broad foci. Papers and posters are sought on traditional aerobiology themes such as the aerial movement and dispersal of spores, pollens, insects, birds, and other aerobiota, atmospheric factors influencing aerial movement of organisms, and new technologies for aerial sampling of biota. In addition, special sessions on future directions in aerobiology are planned. Anticipated themes for these aerobiology sessions include Scientific Challenges in the 21st Century, Technical Challenges in the 21st Century, and Aerobiology Curriculum Development. Participants with additional suggestions for the programs are encouraged to contact the program chairperson.

Student presenters (undergraduate and graduate) are encouraged to apply for student travel grants to attend the confeence. Prizes (\$200) will also be awarded for the best student oral presentation and for the best poster.

The deadline for abstracts is 21 February 2000. Abstracts are now submitted electronically (visit the AMS Web site at http://www.ametsoc.org/AMS or refer page 1951 of the Bulletin or instructions on this new electronic procedure). Authors of accepted abstracts will be notified by early May 2000. A preprint volume is planned and authors of accepted abstracts are encouraged to contribute to this volume. Instructions for formatting extended manuscripts for the preprint volume will be posted on the AMS Web site. Camera-ready manuscripts (page length to be determined), including photos and diagrams, must be submitted by 26 May 2000 to AMS Headquarters. Page charges will be assessed to defray printing costs. Registrants will receive the preprint volume at the conference. For additional information on the sessions please contact the program organizers: Dennis Driscoll (driscoll@ariel.met.tam.edu) for the biometeorology sessions and Scott Isard (s-isard@uiuc.eu) for the aerobiology sessions and student travel grants. (7/99; r8/99)

\section{Call for Papers}

\section{Third Symposium on the Urban Environment, 14- 18 August 2000, Davis, California}

The Third Symposium on the Urban Environment, sponsored by the American Meteorology Society and organized by the AMS Committee on Biometeorology and Aerobiology, will be held 14-18 August 2000 at the University of California, in Davis, California.The conference will be held concurrently with the 24th Conference on Agricultural and Forest Meteorology and the 14th Conference on Biometeorology and Aerobiology. Some sessions will be joint between conferences.

The Third Symposium on the Urban Environment invites posters and papers on all subjects dealing with the urban atmosphere. Observational, modeling, theoretical, and applied studies are all welcome. Sessions will be held to cover themes of urban vegetation-atmosphere interactions, turbulent transport and dispersion processes (in urban areas and around buildings), urban air quality (urban airshed modeling and urban air chemistry experiments), 
measurement challenges and observation techniques in urban environments, urban winds and circulation systems, mesoscale interactions between cities and their surroundings, the energy and water balance of cities, the urban heat island effect and its possible contamination of long-term air temperature records, remote sensing of urban meteorological variables, heat waves and urban biometeorology, models of the urban biosphere, cities as agents of global change, building climate, road climatology, examples of planning and policy changes resulting from urban climate research, urban effects on weather, and weather forecasting for urban areas and city dwellers.

A number of special sessions, which include results and opportunities associated with intensive urban campaigns (e.g. ATLANTA, Urban LTER sites, URGENT, etc.), also are planned. Proposals for other such sessions or for panel discussions are welcome; please contact the program chair as soon as possible and certainly before the due date for abstracts. Participants with additional suggestions for the programs are encouraged to contact the program chairperson.

Awards will be given to students for the best papers and posters. In order to be considered for the competition, students should indicate their intent to participate in this competition when they submit their abstract.

The deadline for abstracts is 21 February 2000. Abstracts are now submitted electronically (visit the AMS Web site at http://www.ametsoc.org/AMS or refer page 1951 of the Bulletin or instructions on this new electronic procedure). Authors of accepted abstracts will be notified by early May 2000. A preprint volume is planned and authors of accepted abstracts are encouraged to contribute to this volume. Instructions for formatting extended manuscripts for the preprint volume will be posted on the AMS Web site. Camera-ready manuscripts (page length to be determined), including photos and diagrams, must be submited by 26 May 2000 to AMS Headquarters. Page charges will be assessed to defray printing costs. Registrants will receive the preprint volume at the conference.

For additional information, contact the program chairperson: Sue Grimmond (e-mail: grimmon@indiana.edu). (7/99; r8/99)

\section{Call for Papers}

\section{3th International Conference on Clouds and Precipitation, 14-18 August 2000, Reno, Nevada}

The 13th International Conference on Clouds and Precipitation, sponsored by the International Commission on Clouds and Precipitation (ICCP), the International Association of Meteorology and Atmospheric Sciences (IAMAS), and the International Union of Geodesy and Geophysics (IUGG) is to be held at the John Ascuaga's Nugget Hotel near the Reno-Tahoe International Airport, 14-18 August 2000. The American Meteorological Society is a cooperating organization.
Papers on all research topics related to clouds and precipitation are welcomed including papers on 1) microphysics of clouds and precipitation, 2) cloud dynamics and structure, 3) cloud-climate interactions, 4) simulation of cloud-scale processes, 5) cloud processes and the mesoscale, 6) interactions between clouds and atmospheric chemistry, 7) instrumentation for cloud physics research, and 8) applications of cloud physics and cloud parameterization. Papers are also welcome on the electrification process and nucleation in the atmosphere as they specifically relate to cloud physics.

There will be poster papers and oral presentations. Most of the meeting will consist of one plenary meeting, with the possibility of parallel sessions on some topics for short periods, depending on the number of papers received. It is hoped that the proceedings will be made available on a $\mathrm{CD}$, so authors will be encouraged to submit an electronic version of their paper.

The deadline for abstracts is 1 December 1999. Authors are encouraged to submit electronically using the Conference Web site http://www.tor.ec.gc.ca/armp/CP_Conf/ CP_Conf.html. If this is not possible, an abstract (maximum 40 words) can be submitted to the program chair, George Isaac, Atmospheric Environment Service, 4905 Dufferin Street, Toronto, ON M3H 5T4, Canada (tel: 416-739-4605; fax: 416-739-4211; e-mail: george.isaac@ec.gc.ca).

Authors will be informed of the status of their abstracts by 1 February 2000. A 2-4 page extended abstract will be required for the conference proceedings by 1 April 2000.

For registration, hotel, and general information, please visit the Web site or contact John Hallett, Atmospheric Sciences Center, Desert Research Institute, 2215 Raggio Parkway, Reno, NV 89512-1095 (tel: 775-677-3117; fax: 775-677-3157; e-mail: hallett@dri.edu). (12/98; r6/99)

\section{6th International Conference on Alpine Meteorol- ogy, 1 1-15 September 2000, Innsbruck, Austria}

The 26th International Conference on Alpine Meteorology will be held 11-15 September 2000 in Innsbruck, Austria. This conference will be organized by the Central Institute for Meteorology and Geodynamics as National Weather Service of Austria, by the University Institutes for Meteorology and Geophysics in Innsbruck and Vienna and by the Austrian Society for Meteorology. The American Meteorological Society is a cooperating organization.

Almost 50 years have elapsed since the first International Conferences on Alpine Meteorology. During this span these conferences always had a tradition in providing a platform for interdisciplinary exchange of information on meteorology, hydrology, and climatology between the researchers and experts in these fields as well as students and the user community. The 26th ICAM 2000 will continue with this tradition and shall be a common ground for encouraging the existence and the progress of international research projects. The conference themes are 1) Mesoscale Alpine Programme (MAP): results especially from the field 
experiment SOP; 2) Alpine Synoptic: diagnostics, nowcasting and forecasting in mountainous terrain application for specific users, e.g. aeronautics; 3 ) Observing Systems: in situ and remote sensing instruments and their use in mountains; 4) Alpine Climatology: long- and short-term variability; sensitivity of the alpine climate with regard to global change; data evaluation and model approach; 5) Hydrology: specific hydrological questions in complex terrain; hydrometeorological risks in the alpine environment; 6) Snow and Ice: alpine nivology and glaciology including avalanche research; and 7) Biometeorology and Environmental Meteorology: role of UV-radiation and ozone, trace gases, air pollution in the alpine environment
The deadline for short abstracts ( 1 page) will be in January 2000. The deadline for extended manuscripts will be in May 2000. For further information see the conference Web site at http://www.zamg.ac.at/ ICAM2000. (5/99)

\section{Call for Papers}

\section{Second SPARC General Assembly on Stratospheric Processes and Their Role in Climate, 6-10 November 2000, Mar del Plata, Argentina}

The Second SPARC General Assembly Stratospheric Processes and their Role in Climate, will be held 6-10 November 2000 in Mar del Plata, Argentina. The second General

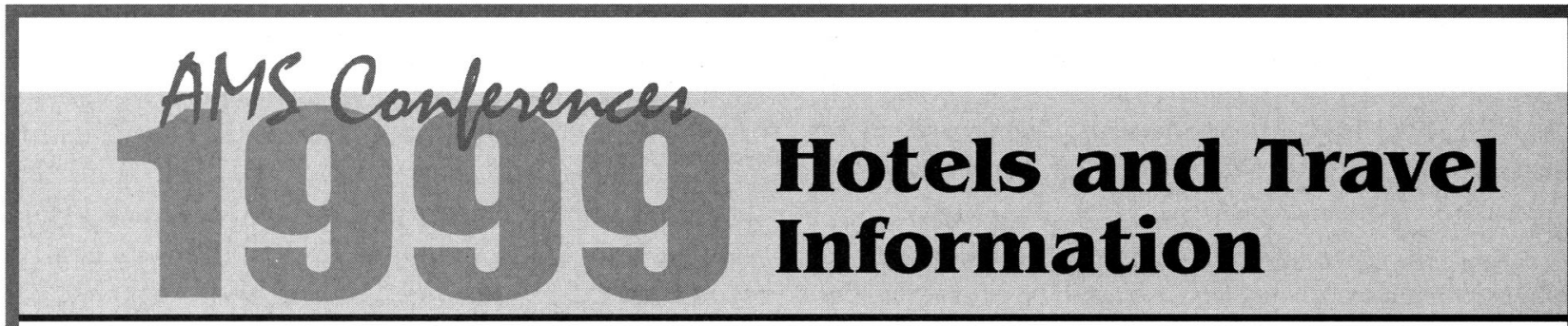

Rooms blocks have been reserved for meeting attendees at the following hotels for 1999 AMS conferences. Fortune International Travel, Inc. (tel: 1-800-622-9998) is the designated travel agency, American Airlines and United Airlines are the designated airlines, and Avis is the designated car rental agency. Discounted rates are available by calling: American Airlines Convention Desk (tel:1-800-433-1790), United Airlines Convention Desk (tel: 1-800-5214041), and Avis Meeting Reservation and Information Desk (tel:1-800-331-1600). Following the hotel information for each conference is the AMS code for American Airlines, United Airlines, and Avis.

\section{7th Conference on Weather Analysis \& Forecasting, 13th Conference on Numerical Weather Prediction, \& 8th Conference on Climate Variations 12-17 September, Denver, Colorado}

Denver Marriott Tech Center 4900 S. Syracuse St., Denver, CO 80237 $\$ 109$ Single/Double

government rate available

American Airlines: 8899UG
800-228-9290 or 303-779-1100 reservations fax: $303-740-2523$

Avis: J945229

\section{Third Conference on Coastal Atmospheric and Oceanic Predictions 3-5 November, New Orleans, Louisiana}

Hampton Inn - Downtown New Orleans 228 Carondelet, New Orleans, LA 70130 \$139 Single, \$149 Double

American Airlines: 67N9UD
United Airlines: 567QG
504-529-9990 or 800-Hampton reservations fax: 504-529-9996

Avis: $J 945229$ 
Assembly of the SPARC project will review current research on the role of the stratosphere in the climate system and in global change. The four sessions will be on the following themes: stratospheric processes and their role in climate, stratospheric indicators of climate change, modelling and diagnosis of stratospheric effects on climate, UV observations and modelling."

The deadline for abstracts is 30 April 2000. For further information please visit the conference Web site at http:// www.sparc2000.at.fcen.uba.ar/, e-mail your inquiry to: sparc2000@at1.fcen.uba.ar, or contact the SPARC Office, CNRS/SA Route des Gâtines - BP 3, 91371 Verrieres-leBuisson Cedex, France (tel : 331644743 15 91371; fax : 33-1 644743 16; www: http://www.aero.jussieu.fr/ sparc/. $(8 / 99)$

\section{Call for Papers}

ISARS2000: 10th International Symposium on Acoustic Remote Sensing, 27 November-1 December 2000, Auckland, New Zealand

The 10th symposium of the International Society for Acoustic Remote Sensing (ISARS) is to be held at the University of Auckland, Auckland, New Zealand, 27 November-1 December 2000. This timing allows delegates the possibility of also attending the Fifth Tropospheric Profiling Conference, to be held in Adelaide Australia from 4-
8 December 2000. The American Meteorological Society is a cooperating organization.

Papers on all aspects of acoustic remote sensing will be welcome, including papers on 1) propagation and scattering of sound in the atmosphere and oceans, 2) instrument development and accuracy, 3) oceanic applications, 4) atmospheric applications, and 5) boundary layer properties. Papers are also particularly welcome on the use of acoustic methodologies in conjunction with other techniques, such as electromagnetic profiling.

The program will include invited papers in selected topics, oral and poster presentations. A social program will also be organized, including a conference dinner and one or more tours of unique New Zealand features. A volume of extended abstracts will be available at the beginning of the conference, in both bound and CD forms: to facilitate this, abstracts and papers will be called for in electronic form. The ISARS Committee also plans to encourage submission of fuller papers for publication in a special issue of one or more selected journals.

For additional information see web site http:// www.phy.auckland.ac.nz/ISARS2000.html or contact Stuart Bradley, Physics Dept., University of Auckland, Private Bag 92019, Auckland, New Zealand (tel: 64-9-3737599 ext. 8899; fax: 64-9-373-7445; e-mail: s.bradley@ auckland.ac.nz). (7/99)

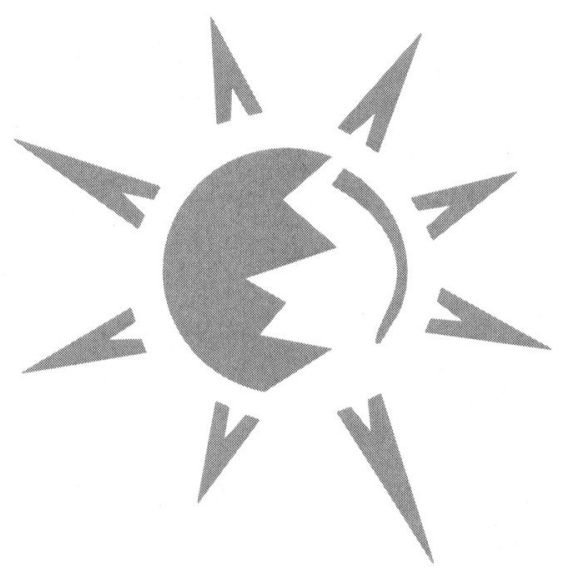

